\title{
Compreendendo o contexto socioeconômico e as estratégias de subsistência de agroecossistemas: Um caminho para a sustentabilidade na agricultura familiar
}

\author{
Understanding the socioeconomic context and livelihood strategies of agroecosystems: A path to
} sustainability in family farming

Comprender el contexto socioeconómico y las estrategias de subsistencia de los agroecosistemas: Un camino hacia la sostenibilidad en la agricultura familiar

\section{Resumo}

O desenvolvimento da agricultura familiar sob a perspectiva agroecológica é uma alternativa para a produção agrícola sustentável. Trata-se de agroecossistemas que atuam de forma positiva para a segurança e a soberania alimentares, embora possuam restrições de recursos, que são um desafio para a sua subsistência. Quanto ao objetivo, neste estudo, avaliaram-se os aspectos ligados ao desempenho da agricultura familiar agroecológica, aplicada a um contexto brasileiro. Mais especificamente, analisaram-se o desdobramento socioeconômico e as dinâmicas de estratégias para a subsistência. O trabalho foi fundamentado em estudos de casos, explorando-se evidências empíricas em três agroecossistemas situados na região nordeste do Brasil. Os dados foram obtidos por meio de métodos interacionais e observações sistemáticas, envolvendo uma equipe multidisciplinar com participação ativa dos agricultores. Os resultados apontaram a necessidade de se alavancarem financeiramente os agricultores familiares de base agroecológica, de forma a viabilizar o desenvolvimento de uma alternativa de produção sustentável. Além disso, identificou-se um contexto agrícola com poucos recursos e várias restrições, mas em que os agricultores resistem e persistem no uso de práticas agroecológicas. Por fim, as abordagens que buscam compreender a realidade dos agricultores, apontando os indicadores socioeconômicos e as estratégias de subsistências, podem ser uma base para a atuação eficiente de organizações e elaboração de políticas públicas que busquem promover uma agricultura sustentável.

Palavras-chave: Agricultura familiar; Subsistência; Desenvolvimento socioeconômico; Sustentabilidade; Práticas agroecológicas.

\begin{abstract}
The development of family farming from an agroecological perspective is an alternative for sustainable agricultural production. These are agroecosystems that act positively for food security and sovereignty, although they have resource constraints, which are a challenge for their livelihoods. As for the objective, in this study, aspects related to the performance of agroecological family farming, applied to a Brazilian context, were evaluated. More specifically, the socioeconomic development and dynamics of livelihood strategies were analyzed. The work was based on case studies, exploring empirical evidence in three agroecosystems located in the northeast region of Brazil. Data were obtained through interactional methods and systematic observations, involving a multidisciplinary team with the
\end{abstract}


active participation of farmers. The results pointed to the need to financially leverage agroecologically-based family farmers, in order to enable the development of an alternative for sustainable production. In addition, an agricultural context was identified with few resources and several restrictions, but in which farmers resist and persist in the use of agroecological practices. Finally, approaches that seek to understand the reality of farmers, pointing out socioeconomic indicators and livelihood strategies, can be a basis for the efficient performance of organizations and the elaboration of public policies that seek to promote sustainable agriculture.

Keywords: Family farming; Subsistence; Socio-economic development; Sustainability; Agroecological practices.

\section{Resumen}

El desarrollo de la agricultura familiar desde una perspectiva agroecológica es una alternativa para la producción agrícola sostenible. Estos son agroecosistemas que actúan positivamente para la seguridad y soberanía alimentaria, aunque tienen limitaciones de recursos, que son un desafío para sus medios de vida. En cuanto al objetivo, en este estudio se evaluaron aspectos relacionados con el desempeño de la agricultura familiar agroecológica, aplicados a un contexto brasileño. Más específicamente, se analizó el desarrollo socioeconómico y la dinámica de las estrategias de medios de vida. El trabajo se basó en estudios de caso, explorando evidencia empírica en tres agroecosistemas ubicados en la región noreste de Brasil. Los datos se obtuvieron a través de métodos interactivos y observaciones sistemáticas, involucrando un equipo multidisciplinario con la participación activa de los agricultores. Los resultados apuntaron a la necesidad de apalancar financieramente a los agricultores familiares de base agroecológica, a fin de posibilitar el desarrollo de una alternativa de producción sostenible. Además, se identificó un contexto agrícola con pocos recursos y varias restricciones, pero en el que los agricultores resisten y persisten en el uso de prácticas agroecológicas. Finalmente, los enfoques que buscan comprender la realidad de los agricultores, señalando indicadores socioeconómicos y estrategias de vida, pueden ser la base para el desempeño eficiente de las organizaciones y la elaboración de políticas públicas que buscan promover una agricultura sostenible.

Palabras clave: Agricultura familiar; Subsistencia; El desarrollo socioeconómico; Sustentabilidad; Prácticas agroecológicas.

\section{Introdução}

Os desafios para um mundo sustentável têm gerado debates constantes na sociedade, de modo que a Organização das Nações Unidas (ONU) fez um chamado global para os países e a população mundial, conjuntamente, construírem metas e objetivos para alcançarem o desenvolvimento sustentável (ONU, 2015). Entre os objetivos definidos, cita-se o denominado Objetivo 2, que visa erradicar a fome, atingir a segurança alimentar e fomentar a agricultura sustentável (ONU, 2015).

Nesse contexto, observa-se a relação intrínseca entre agricultura e sistemas alimentares. Conforme o que Hilmi (2019) destaca, o desempenho da agricultura influencia o bem estar da humanidade, gerando impactos diretos na segurança alimentar. Embora 60\% das terras agrícolas mundiais são destinadas para a atividade pecuária (UNEP, 2020), conjectura-se a marca de 135 milhões de pessoas no mundo passando fome, estimativas estas que podem ser agravadas com a recessão econômica causada pela pandemia mundial da Doença por Coronavírus - 2019 ou Coronavirus Disease 2019 (COVID-19) (FSIN, 2020).

Para minimizar os problemas da fome no mundo, é crucial que os sistemas alimentares sejam eficientes (Altieri \& Nicholls, 2017), a partir do desenvolvimento de comunidades agrícolas com economias saudáveis em equilíbrio com o meio ambiente (Hilmi, 2019). Nessa concepção de desenvolvimento fundamentada em uma produção agrícola sustentável, considera-se a gestão estratégica dos recursos dos agroecossistemas (Bezerra et al., 2018; Mthembu et al., 2019).

É nesse contexto que tanto os cientistas como as organizações sociais buscam promover um modelo de produção baseado na agroecologia (Altieri \& Nicholls, 2017; Teixeira et al., 2018, UNEP, 2020). Trata-se de um redesenho dos sistemas agrícolas convencionais, de modo que, por meio de abordagens ecológicas, busca-se o equilíbrio entre produção e ecossistema; além disso, esse modelo compreende uma perspectiva de sistema holístico que envolve aspectos econômicos, políticos, sociais, culturais e ambientais (Altieri, Funes-Monzote, \& Petersen, 2012; Gliessman, 2018; Guerra et al., 2017; Timmermann \& Félix, 2015; Vaarst et al., 2018).

Ademais, a adoção de sistemas agroecológicos contribui para a conservação da biodiversidade, esta que exerce uma importante função para a regulação e o desempenho dos serviços ecossistêmicos (Altieri et al., 2012; Loyola, 2016). Ressaltase que preservar a biodiversidade permite aumentar o sequestro de carbono, além de manter o controle de pragas e doenças, 
minimizando os riscos de acontecerem futuras pandemias (Guerra et al., 2017; UNEP, 2020). Cabe considerar que a biodiversidade e as mudanças climáticas estão fortemente relacionadas (Altieri \& Nicholls, 2017), por conseguinte, envolvem a atividade agrícola e seus impactos negativos quando esta é desenvolvida de forma ineficiente (FAO, 2013).

Estudos comparativos com base nos pilares da sustentabilidade demonstram a eficiência dos sistemas agroecológicos em detrimento dos sistemas agrícolas convencionais, ressaltando o diferencial colaborativo com os sistemas alimentares (Capellesso et al., 2016; Jacobi et al., 2018; Lucantoni et al., 2018; Soldi et al., 2019). Jacobi et al. (2018) fazem um acréscimo, ao dizerem que nos sistemas agroecológicos há uma riqueza de capital natural e humano; Soldi et al. (2019) estendem essa discussão, ao mencionarem a eficiência da utilização do trabalho manual para a potencialização do uso da terra e de sementes nativas que ocasionam resultados positivos na rentabilidade da propriedade agrícola.

Em uma outra perspectiva, Capellesso et al. (2016) expõem a relação inversa entre o aumento da produtividade dos sistemas agrícolas que fazem uso intensivo de insumos químicos com a diminuição do retorno sobre o capital investido. Em sistemas agroecológicos, não se faz alto investimento em insumos externos; as sinergias das práticas realizadas e as reciclagens de resíduos reduzem os custos, uma vez que nesses sistemas se produz parte dos recursos necessários para a produção agrícola, assim como para a subsistência da família (Dumont et al., 2018; Hilmi, 2019; Rasse et al., 2018).

Nota-se que os sistemas agroecológicos são adequados aos pequenos agricultores familiares (Larrauri et al., 2016; Trevisan et al., 2016), sendo estes os responsáveis por mais da metade da produção de alimentos do mundo, representando 90\% das propriedades agrícolas mundiais, que são dependentes sobretudo da mão de obra familiar (FAO, 2014, 2017; Graeub et al., 2016; Kangmennaang et al., 2017). Atuam de uma forma positiva para a segurança e soberania alimentares, embora a maioria se encontre entre os grupos que representam os mais vulneráveis à pobreza e à fome nas áreas rurais (FAO, 2017).

As principais dificuldades de se desenvolver a agricultura familiar são evidenciadas na literatura como a falta de apoio financeiro (Hilmi, 2019), dificuldades de acesso a mercados (Valencia et al., 2019) e as limitadas políticas públicas (Massicotte \& Kelly-Bisson, 2019). Além disso, destacam-se as restrições estruturais, como a disponibilidade de mão-de-obra e de redes de apoio que são limiares aos agricultores familiares para que estes possam adotar estratégias agroecológicas (Valencia et al., 2019).

Dessa forma, as restrições limitam as decisões do gestor familiar. Conforme o que Timmermann e Félix (2015) esclarecem, esses gestores dependem da produção da propriedade para garantirem o autoconsumo da família. Assim, as estratégias utilizadas são norteadas pela estrutura social do contexto socioeconômico em que estão situados os agricultores familiares (Guerra et al., 2017; Schneider, 2003), voltadas para a subsistência, tais como decisões de intercâmbio dos elementos dos ativos (exemplo, vendas da produção animal para comprar insumos vegetais), recursos físicos disponíveis, rendas, processos e as vulnerabilidades tanto de mercado como ambientais (Goswami et al., 2017).

$\mathrm{Na}$ busca de compreenderem as dinâmicas estratégicas voltadas para a subsistência no meio rural, alguns pesquisadores utilizaram a abordagem de ativos de capitais, ou seja, para entenderem as estratégias na perspectiva dos recursos humano, físico, natural, financeiro e social (Barrett \& Swallow, 2004; Bebbington, 1999; Ellis, 2000; Krantz, 2001). Uma noção sobre o acesso a esses recursos de capitais potencializa o entendimento da relação entre necessidade e escolhas estratégicas, assim como das possibilidades para aumentar a qualidade de vida e responder à determinada condição social (Bebbington, 1999).

Além disso, o acesso aos ativos de capitais depende das condições estruturais do ambiente em que os agricultores estão inseridos, envolvendo desde aspectos econômicos, políticos, tecnológicos até as características dos membros familiares (Bebbington, 1999). A família torna-se uma referência de análise, pois fatores da sua composição, a exemplo da idade, do grau de escolaridade e do capital, são aspectos que potencializam as estratégias de subsistência adotadas (Meert et al., 2005).

Complementando-se o que Timmermann e Félix (2015) mencionam sobre a complexidade socioeconômica que 
envolve o agricultor e a família, considera-se que tanto a produtividade como a capacidade de gerar renda podem influenciar o desenvolvimento de práticas agroecológicas. Ainda, conforme o que dizem esses mesmos autores, quando a produção agrícola é a principal fonte de renda familiar, os produtos agrícolas necessitam ser vendidos para se garantir a renda; nestes casos, ações criativas e inventivas são indispensáveis para se devolverem estratégias comerciais e se superarem as adversidades ambientais e do mercado de forma a se garantir a subsistência familiar.

Para Ploeg (2008), a subsistência relaciona-se com resiliência e autonomia nos sistemas agroecológicos, os quais, com menor dependência externa de insumos, diversidade funcional e auto aprovisionamento de sementes e alimentos, restringem os impactos das vulnerabilidades dos preços de mercado, amplificando o controle dos agricultores sobre as decisões do que produzir e comercializar (Dumont et al., 2018; Hilmi, 2019; Valencia et al., 2019).

Por outro lado, o acesso estável de agricultores familiares de base agroecológica ao mercado fortalece o comércio local e promove segurança alimentar, disponibilizando à comunidade uma diversidade de produtos que favorecem a dieta alimentar (Valencia et al., 2019). Complementando-se essa ideia, pode-se dizer que os agricultores familiares promovem a prosperidade local e global, são uma alavanca contra a pobreza rural, propiciam a empregabilidade na localidade, geram renda, conservam ecossistemas e suprem os mercados (Cochet, 2015; Goswami et al., 2017; Hilmi, 2019).

Nesse contexto, os estudos citados evidenciam que a análise da agricultura familiar de base agroecológica é de interesse global e local, considerando-se fundamental a compreensão tanto do contexto socioeconômico como das estratégias de subsistência adotadas, de forma a promover oportunidades a esses pequenos agricultores. No entanto, dados na literatura sobre indicadores socioeconômicos são limitados (D’Annolfo et al., 2017; Garibaldi et al., 2017), sendo em sua grande maioria revisões teóricas, tornando-se imprescindíveis estudos de casos quanti-qualitativos para uma melhor compreensão do desempenho socioeconômico dos sistemas agroecológicos e, assim, contribuir para o desenvolvimento de estratégias e a formação de políticas que apoiem a sustentabilidade.

Por sua vez, Dalsgaard (1997) menciona os benefícios de avaliação de desempenho de pequenas propriedades rurais de base agroecológica como sistemas de produção (agroecossitemas). É a partir de uma perspectiva sistêmica, considerando-se todos os seus componentes e as suas relações, que se torna possível compreender e evidenciar a capacidade produtiva dos sistemas agroecológicos e seus ganhos intangíveis (Dalsgaard, 1997; Solis \& Rivera, 2018; Thomazini et al., 2013).

A partir das considerações expostas acima, neste trabalho, tem-se o objetivo de examinar os aspectos ligados ao desempenho da agricultura familiar agroecológica, aplicada em um contexto brasileiro. Especificamente, analisam-se o desdobramento socioeconômico e as dinâmicas de estratégias para a subsistência.

O contexto brasileiro foi escolhido por ser um país que tem acentuada concentração de produção e renda na atividade agrícola, estando a maior parte dos agricultores entre os denominados pobres ou extremamente pobres, estes mais presentes nas regiões norte e nordeste do país (Bolfe, 2018). Dados do último censo agrícola realizado em 2017 mostram que, dos estabelecimentos agropecuários, $77 \%$ são classificados como agricultura familiar, representam 67\% de pessoas empregadas e ocupam apenas 23\% das áreas utilizadas (IBGE, 2019). Além disso, constatou-se o aumento de $20 \%$ de uso de agrotóxico entre 2006 e 2017 nos estabelecimentos agrícolas, assim como se evidenciou a vazão do homem do campo e, especificamente na agricultura familiar, observou-se que 73\% dos agricultores tinham 45 anos ou mais (IBGE, 2019).

Cabe mencionar que no Brasil as políticas públicas para o desenvolvimento agrícola são concentradas no estímulo ao agronegócio, potencializando um tipo de agricultura ineficiente, com altos custos ambientais e sociais (Capellesso et al., 2016; Wittman \& Blesh, 2017), de modo que, na presente pesquisa, a partir de estudos de casos brasileiros, busca-se explorar aspectos específicos de indicadores socioeconômicos e estratégias de subsistência, compreendendo-se que essas considerações podem ser úteis para se nortearem decisões pontuais nas áreas rurais, particularmente quanto ao desenvolvimento de uma agricultura sustentável. 
Além disso, o sistema de produção agroecológico é um caminho para desenvolver uma agricultura sustentável (Altieri et al., 2015; Araújo et al., 2013). Revisões de Díez et al. (2018) e Emeana et al. (2018) evidenciam lacunas de investigações empíricas, enquanto Massicotte e Kelly-Bisson (2019) o fazem particularmente nas esferas locais e regionais. Outros autores, a exemplo de Larrauri et al. (2016) consideram a investigação empírica imprescindível para se avançar nesse campo de conhecimento, envolvendo a agricultura sustentável. Ademais, há um apelo de estudos de casos que abordem contextos locais, e este estudo começa a explorar essas lacunas, de forma a contribuir para o avanço de pesquisas sobre sistemas agroecológicos.

O presente trabalho está estruturado em quatro seções. Nesta primeira seção, contextualizaram-se os sistemas agroecológicos e buscou-se evidenciar a relevância de se compreenderem os indicadores socioeconômicos e as estratégias de subsistência adotadas. Na segunda seção, apresenta-se o método de pesquisa, conduzido nos estudos de caso. Na terceira seção, por sua vez, apresentam-se os resultados da pesquisa de campo. Por fim, na quarta seção, apresentam-se as considerações finais, contribuições, limitações do estudo e projeções para novos estudos envolvendo essa temática.

\section{Metodologia}

Os aspectos metodológicos desta pesquisa serão apresentados em duas seções, na primeira, para tratar da região de estudo, e, na segunda, dos métodos empregados.

\subsection{Região de Estudo}

Para a execução prática deste trabalho, considerando-se a necessidade da pesquisa e as oportunidades ora encontradas, o contexto que propiciou a aplicação dos indicadores de desempenho está situado na região semiárida do Estado da Paraíba, Brasil, especificamente, no Território da Borborema-PB. Para uma localização geográfica, na Figura 1, apresenta-se um mapa adaptado do referido Território, situado na Mesorregião do Agreste Paraibano, abrangendo uma área de 3.341,7 km² e constituído por 21 municípios, dentre os quais, 12 (Alagoa Nova, Arara, Areial, Casserengue, Esperança, Lagoa de Roça, Lagoa Seca, Massaranduba, Montadas, Queimadas, Remígio e Solânea) vêm adotando um modelo de produção familiar agroecológico (Saldanha et al., 2018).

Figura 1 - Localização do Território da Borborema - Paraíba - Brasil.

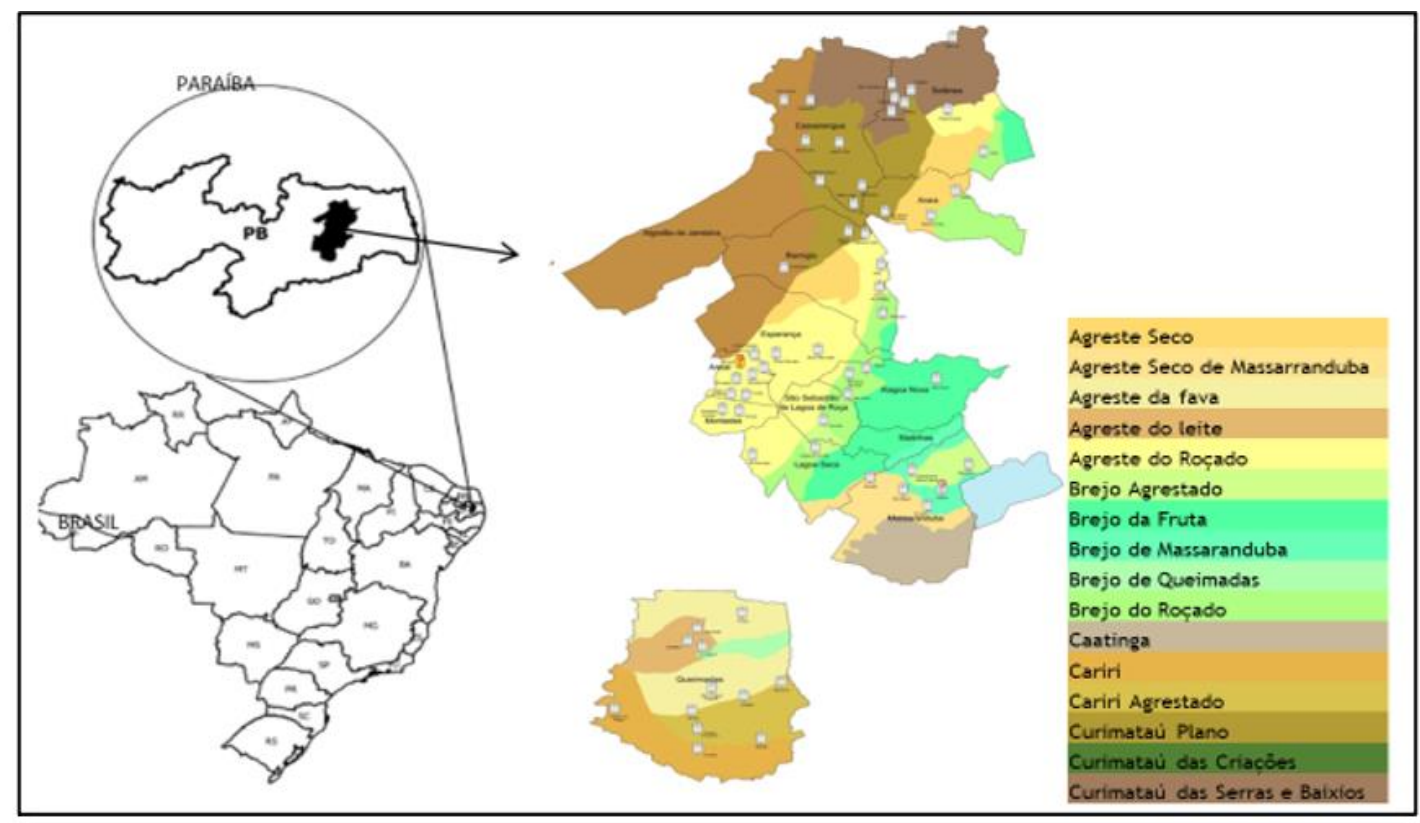

Fonte: Adaptado de Saldanha et al. (2018). 
Os agricultores familiares de base agroecológica da Borborema são apoiados e organizados por entidades que fortalecem o desenvolvimento de uma produção agrícola sustentável (Saldanha et al., 2016), a exemplo da Ecoborborema, uma associação de pequenos agricultores agroecológicos do território que se organizam para vender sua produção nas feiras e para lojistas da Paraíba e outros estados; da AS-PTA Agricultura Familiar e Agroecologia, uma organização não governamental com atuação nacional que busca fortalecer a agricultura familiar e o desenvolvimento rural sustentável; e também dos sindicatos rurais e dos agricultores, as quais se articulam para influenciarem a implantação e o desenvolvimento de políticas públicas (Sobrinho \& Ramos, 2016).

Quanto às características ambientais do território, destaca-se alta imprevisibilidade pluviométrica (Petersen et al., 2013) e ciclos de estiagem prolongados (Paraíba, 2010). As chuvas são mais frequentes entre os meses de fevereiro e março, prolongando-se até agosto; a estiagem, por sua vez, compreende um período de 5 a 6 meses (Paraíba, 2010). No que se refere aos solos, são profundos e relativamente férteis; em relação à hidrografia, há rios classificados como semi-perenes (temporários) e, no que diz respeito ao fluxo d'água, este oscila entre os períodos secos e chuvosos (Paraíba, 2010).

\subsection{Métodos}

Para se atingirem os objetivos, o estudo foi aplicado em três pequenas propriedades rurais, com gestão familiar e de base agroecológica, delimitadas como sistema de produção, o qual, neste trabalho, foi definido como agroecossistema (Dalsgaard, 1997). Foi conduzida uma pesquisa qualitativa e quantitativa com a utilização de método de casos múltiplos, abordagem esta aplicada com o propósito de se compreender melhor o contexto de cada agroecossistema (Eisenhardt \& Graebner, 2007).

A seleção dos agroecossistemas foi baseada em indicação técnica da AS-PTA, considerando-se as necessidades inerentes à presente pesquisa e a disponibilidade dos agricultores; logo, trata-se de uma amostra não probabilística por conveniência. Os critérios para seleção foram os seguintes: i) produção total guiada na perspectiva da conservação e manejo dos recursos naturais e sob a ótica agroecológica; ii) localizações próximas, com características semelhantes de microclimas, relevo e paisagens; iii) sem sistema de irrigação.

A pesquisa de campo foi realizada com a colaboração da AS-PTA, de forma a se criar um ambiente de confiança para a coleta das informações necessárias, em um processo de construção conjunta e multidiciplinar, assim, permitindo a compreensão da realidade e o contexto de forma integrada. Para isso, foram aplicados métodos interacionais (entrevista semiestruturada, ação conversacional, verbalização e aplicação de protocolos específicos) e observacionais, de forma que envolvesse a participação ativa dos agricultores, tornando-os protagonistas no processo das informações.

Para auxiliar no entendimento do desempenho das propriedades envolvidas, em uma perspectiva sistêmica, foi realizada uma caracterização do contexto agrícola. Para isso, citam-se os achados identificados em Saldanha et al. (2016), que apresentaram algumas características da agricultura familiar agroecológica da região, como também em Saldanha et al. (2018), que propõem uma metodologia de sistema de indicadores para a agricultura familiar de base agroecológica (AGROINDEX), partindo da premissa de que, para a concepção de indicadores de desempenho no contexto da agricultura familiar de base agroecologica, primeiramente, deve-se compreender as características e diversidades locais.

Para aprofundar a compreensão da realidade estudada, os presentes pesquisadores participaram de reuniões e eventos que envolviam os agricultores, destacando os que foram promovidos pela AS-PTA. As visitas aos locais de produção aconteceram em três períodos distintos, observando-se os ciclos produtivos e a disponibilidade dos pesquisados. As entrevistas aconteceram com o gestor da propriedade e sua esposa no primeiro caso (Agro 1); no segundo (Agro 2), ocorreu com o gestor e uma das suas filhas; e, no terceiro (Agro 3), com a gestora da propriedade.

Os preceitos para se levantarem os indicadores socioeconômicos foram consistentes com Petersen et al. (2017), Ploeg 
(2008) e Ploeg et al. (2019), conforme aspectos especificados no Quadro 1. Os dados referem-se ao ciclo anual de 2019, organizados em planilhas de excel, subdivididas em um formato que permitisse a visualização de informações individualizadas dos subsistemas de produção animal (bovinos, aves, suínos, caprinos e ovinos) e vegetal (roçados, quintais, forragem e outros).

Quadro 1 - Indicadores socioeconômicos.

\begin{tabular}{|c|c|c|}
\hline CATEGORIA & INDICADORES & ASPECTOS \\
\hline \multirow{11}{*}{ 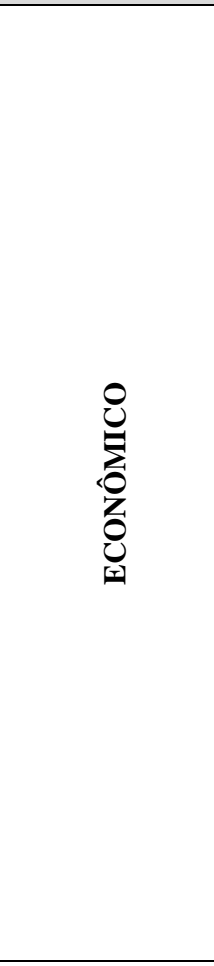 } & Rendas não Agrícolas (RnA) & $\begin{array}{l}\text { Compostas por rendas de pluriatividades (trabalho assalariado, turismo rural, } \\
\text { artesanato) e transferência de renda (previdência, bolsa família, seguro safra). }\end{array}$ \\
\hline & Rendas Agrícolas (RA) & $\begin{array}{l}\text { Valores agregados, diminuídos dos valores pagos a terceiros (diaristas, } \\
\text { arrendadores, assalariados). }\end{array}$ \\
\hline & Produto Bruto $(\mathrm{PB})$ & $\begin{array}{l}\text { Representa a soma de todos os produtos obtidos no agroecossistema para o } \\
\text { período analisado }(\mathrm{PB}=\text { vendas }+ \text { autoconsumo }+ \text { trocas/doações }+ \text { estoque). }\end{array}$ \\
\hline & Valor Agregado (VA) & $\begin{array}{l}\text { Somatório dos valores da produção vendida, autoconsumida e doada e/ou } \\
\text { trocada, diminuída do custo intermediário. Representa a nova riqueza gerada pelo } \\
\text { trabalho do agroecossistema. }\end{array}$ \\
\hline & Custos Intermediários (CI) & $\begin{array}{l}\text { Insumos adquiridos nos mercados e que são integramente utilizados no processo } \\
\text { produtivo. }\end{array}$ \\
\hline & Custos de Produção (CP) & $\begin{array}{l}\text { Somatório dos valores dos custos intermediários comprados e o pagamento de } \\
\text { serviços de terceiros. Incluem-se os gastos de energia elétrica, mensalidade de } \\
\text { associações e sindicatos. }\end{array}$ \\
\hline & Rentabilidade (R) & $\begin{array}{l}\text { Equivale à razão do valor agregado (VA) pelos custos intermediários }(\mathrm{CI})(\mathrm{R}= \\
\text { VA/CI). Corresponde ao VA por unidade de CI investido na produção. }\end{array}$ \\
\hline & Insumos & $\begin{array}{l}\text { Matéria-prima para a produção, como a forragem (armazenada nos silos) e } \\
\text { sementes dos bancos familiares e comunitários. }\end{array}$ \\
\hline & Estoques de Produtos & $\begin{array}{l}\text { Correspondem aos produtos (grãos) armazenados que serão realizados } \\
\text { economicamente em período posterior, em forma de vendas, consumo ou } \\
\text { doações/trocas. }\end{array}$ \\
\hline & Capital Vivo (semoventes) & $\begin{array}{l}\text { Representa os animais do agroecossistema, inventariados por espécie e categoria } \\
\text { de valor, conforme a descrição e estimativas dos entrevistados. }\end{array}$ \\
\hline & Reciprocidade Ecológica & $\begin{array}{l}\text { Insumos produzidos no agroecossistema a partir da interação do trabalho humano } \\
\text { e da natureza. Os valores indicados são aproximados, conforme percepção e } \\
\text { mensuração dos entrevistados. }\end{array}$ \\
\hline \multirow{5}{*}{ ¿ֶ } & Renda per Capita & $\begin{array}{l}\text { Divisão das rendas (rendas agrícolas mais rendas não agrícolas) pelo número de } \\
\text { pessoas do núcleo familiar. }\end{array}$ \\
\hline & Horas Trabalhadas & $\begin{array}{l}\text { Estimativa do número de horas trabalhadas nas atividades agrícolas e domésticas } \\
\text { conforme descrição dos entrevistados. }\end{array}$ \\
\hline & Núcleo Familiar & Representa o número de pessoas dependentes do agroecossistema. \\
\hline & Participação Social & $\begin{array}{l}\text { Estimativa conforme a percepção do agricultor quanto às horas destinadas às } \\
\text { participações em reuniões da associação, sindicato e reuniões/eventos da AS- } \\
\text { PTA. }\end{array}$ \\
\hline & Múltiplos Domicílios & Mais de um núcleo familiar - residência na área total da propriedade rural. \\
\hline
\end{tabular}

Fonte: Adaptado a partir de Petersen et al. (2017), Ploeg (2008) e Ploeg et al. (2019).

Levando-se em consideração o quadro acima, para cada subsistema, foram levantadas, de forma unitária e total, as quantidades e valores em reais $(\mathrm{R} \$)$ das vendas, autoconsumo, doações/trocas, estoques, reciprocidade ecológica, consumos intermediários e os pagamentos realizados a terceiros. Os valores monetários foram baseados no preço do mercado local, considerando-se as estimativas de vendas dos agricultores. No caso de itens com ausência de referenciais de preços, foi utilizada uma tabela de mercado disponibilizada pela AS-PTA, estabelecida nas vendas com assessoria dessa associação.

É necessário considerar que houve reservas de insumos e de estoques de ciclos econômicos anteriores, mas, dadas as dificuldades para dimensioná-las, considerando-se que os agricultores não fazem registros, elas foram assumidas como rendas do período analisado. Conforme o que Petersen et al. (2017) esclarece, essa estratégia metodológica não compromete a análise, dado certo nível de compensação, pois o esforço de trabalho realizado no período é investido em produtos e insumos que são estocados, somente transformados em rendas nos ciclos econômicos posteriores.

Quanto às análises de estratégias de subsistência, foram aplicadas as dimensões indicadas em Barrett e Swallow 
(2004), Bebbington (1999), Ellis (2000) e Krantz (2001). As dimensões abordam o capital humano (idade do responsável pelo agroecossistema, o nível de escolaridade, componente familiar residente no agroecossistema com trabalho não agrícola, razão do número de homens pelo de mulheres e mão de obra paga a terceiros); capital físico (tamanho da propriedade em hectares e a disponibilidade de cisternas); capital natural (quantidades de animais e dos recursos vegetais); capital financeiro (renda familiar: percentual da renda proveniente da agricultura, das transferências governamentais e pluriatividades e renda monetária per capita); capital social (propriedade rural com mais de um domicílio, estimativa em horas anuais de partipação social e participação do gestor em representação da comunidade rural em que o agroecossistema está situado).

Por fim, a análise e a discussão dos dados foram realizadas de acordo com os objetivos da pesquisa. Iniciamente, foi compreendido o contexto dos agroecossistemas; em seguida, estabeleceu-se uma discussão comparativa entre os agroecossistemas, considerando-se os desdobramentos socioeconômicos e as dinâmicas das estratégias de subsistências. Essas discussões são apresentadas na próxima seção.

\section{Resultados e Discussão}

Os resultados deste trabalho são apresentados em três etapas: i. contexto sistêmico, envolvendo o modelo de sistema de produção; ii. evidências do desempenho socioeconômico; e iii. estratégias de subsistência.

\subsection{Contexto Sistêmico: modelo de sistema de produção}

Uma questão fundamental para a compreensão dos agroecossistemas foi estabelecer uma representação esquemática, de forma a se compreender o funcionamento do sistema de produção praticado no Território da Borborema - PB. Na Figura 2, apresenta-se um modelo sistêmico das propriedades envolvidas no estudo, expondo a integração entre as produções vegetal e animal, os seus componentes (subsistemas) e os diferentes fluxos e intercâmbios (insumos, produtos e renda) a elas relacionados.

Figura 2 - Modelo do sistema de produção.

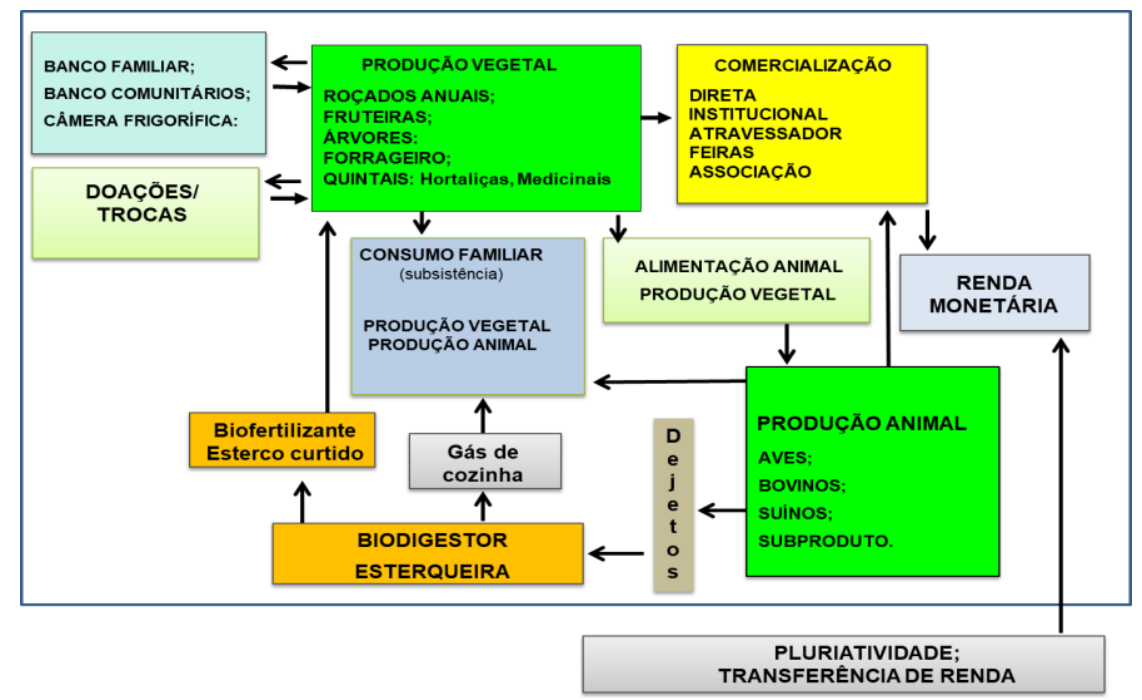

Fonte: Adaptado de Saldanha et al. (2016).

Cabe destacar que cada agroecossistema apresentou suas peculiaridades, mas um ponto em comum foi o fato de terem demonstrado uma diversidade de produção vegetal, subdividida em: culturas anuais (roçados); fruteiras; árvores e cerca-viva; forrageiras e quintais, estes últimos subdivididos entre hortaliças e plantas medicinais. A produção animal é subdividida em 
bovinos, suínos, caprinos, ovinos e aves. Ademais, houve particularidades na produção de esterco e fertilizantes naturais, isto para estimular a produção vegetal, a partir de folhagens de plantios e o uso dos dejetos animais, além do gás de cozinha produzido pelo biodigestor (Ver Quadro 2).

Considerando-se os aspectos distintos de cada agroecossistema e as integrações, tem-se um modelo de produção complexo, expondo sinergias que fornecem amplos serviços ecossistêmicos, difíceis de serem mensuradas. De uma forma multifuncional, a produção vegetal é direcionada para o consumo familiar, comercialização e forragem, enquanto a produção animal, para o consumo familiar e comercialização; ressalta-se, ainda, o escoamento da produção vegetal para os bancos de sementes familiares e comunitários, como forma de suprir demandas de plantios futuros.

No Quadro 2, demonstram-se todas as variedades de produções vegetal e animal que foram identificadas nos agroecossistemas. É comum a todos esses agroecossistemas as variedades de produções, considerando-se que, na agricultura de ótica agroecológica, a diversidade é uma característica determinante, uma vez que promove integração e sustentabilidade da produção.

Quadro 2 - Diversidades nos agroecossistemas.

\begin{tabular}{|c|c|c|c|c|c|c|c|c|c|c|c|c|c|c|c|c|c|c|c|}
\hline \multirow{2}{*}{\multicolumn{2}{|c|}{$\begin{array}{c}\text { SUBSISTEMAS/VARIED } \\
\text { ADES }\end{array}$}} & \multicolumn{6}{|c|}{ AGRO 1 } & \multicolumn{6}{|c|}{ AGRO 2} & \multicolumn{6}{|c|}{ AGRO 3} \\
\hline & & \multirow{2}{*}{\begin{tabular}{|l|}
$\mathbf{P}$ \\
$\mathbf{R}$ \\
$\mathrm{X}$ \\
\end{tabular}} & \multirow{2}{*}{$\begin{array}{l}\mathbf{C} \\
\mathrm{F} \\
\mathrm{X} \\
\end{array}$} & \multirow{2}{*}{$\begin{array}{l}\mathbf{C} \\
\mathbf{A} \\
\end{array}$} & \multirow{2}{*}{$\begin{array}{l}\mathbf{E} \\
\mathbf{S} \\
\mathrm{X} \\
\end{array}$} & \multirow{2}{*}{$\begin{array}{l}\mathrm{D} / \\
\mathrm{T}\end{array}$} & $\begin{array}{l}\mathbf{C} \\
\mathbf{O}\end{array}$ & $\begin{array}{l}\mathbf{P} \\
\mathbf{R}\end{array}$ & $\begin{array}{l}\mathbf{C} \\
\mathbf{F}\end{array}$ & $\begin{array}{l}\mathbf{C} \\
\mathbf{A}\end{array}$ & $\begin{array}{l}\mathbf{E} \\
\mathbf{S} \\
\end{array}$ & $\begin{array}{l}\mathbf{D} / \\
\mathbf{T}\end{array}$ & $\begin{array}{l}\mathbf{C} \\
\mathbf{O}\end{array}$ & $\begin{array}{l}\mathbf{P} \\
\mathbf{R} \\
\end{array}$ & $\begin{array}{l}\mathbf{C} \\
\mathbf{F}\end{array}$ & $\begin{array}{l}\text { C } \\
\text { A }\end{array}$ & \multirow{2}{*}{$\begin{array}{l}\mathbf{E} \\
\mathbf{S} \\
\mathrm{X} \\
\end{array}$} & \multirow{2}{*}{$\begin{array}{c}\mathbf{D} / \\
\mathbf{T} \\
\end{array}$} & C \\
\hline & Batata Doce & & & & & & & $\bar{x}$ & $\mathrm{x}$ & & & $\mathrm{x}$ & & $\mathrm{x}$ & $\mathrm{x}$ & $\mathrm{x}$ & & & \\
\hline & Batatinha & $\mathrm{x}$ & $\mathrm{x}$ & $\mathrm{x}$ & & & & $\mathrm{x}$ & $\mathrm{x}$ & & & & $\mathrm{x}$ & $\bar{x}$ & $\mathrm{x}$ & & & & \\
\hline & Erva-Doce & $\mathrm{x}$ & $\mathrm{x}$ & & $\mathrm{x}$ & & $\mathrm{x}$ & $\mathrm{x}$ & $\mathrm{x}$ & & & & & $\mathrm{x}$ & $\mathrm{x}$ & & & & \\
\hline & Fava Boca de Moça & & & & & & & $\mathrm{x}$ & $\mathrm{x}$ & & & & & $\mathrm{x}$ & $\mathrm{x}$ & & & & \\
\hline & Fava Catatuba & $\mathrm{x}$ & $\mathrm{x}$ & & & & $\mathrm{x}$ & $\mathrm{x}$ & $\mathrm{x}$ & & & & & $\mathrm{x}$ & $\mathrm{x}$ & & $\mathrm{x}$ & & $\mathrm{x}$ \\
\hline & Fava Eucalipto & $\mathrm{x}$ & $\mathrm{x}$ & & & & $\mathrm{x}$ & $\mathrm{x}$ & $\mathrm{x}$ & & & & & $\mathrm{x}$ & $\mathrm{x}$ & & $\mathrm{x}$ & & $\mathrm{x}$ \\
\hline & Fava Moita & $\bar{x}$ & $\mathrm{x}$ & & $\mathrm{x}$ & & $\mathrm{x}$ & $\mathrm{x}$ & $\mathrm{x}$ & & $\mathrm{x}$ & & & $\bar{x}$ & $\mathrm{x}$ & & & & \\
\hline & Fava Orelha de Vó & & & & & & & $\mathrm{x}$ & $\mathrm{x}$ & & & & & $\bar{x}$ & $\mathrm{x}$ & & $\mathrm{x}$ & & \\
\hline & Feijão Bico de Ouro & & & & & & & $\bar{x}$ & $\mathrm{x}$ & & $\mathrm{X}$ & $\mathrm{x}$ & & & & & & $\mathrm{x}$ & \\
\hline & Feijão Carioca & $\mathrm{x}$ & $\mathrm{x}$ & & $\mathrm{x}$ & & $\mathrm{x}$ & & & & & & & & & & & & \\
\hline & Feijão Carioquinha & $\bar{x}$ & $\mathrm{X}$ & & & & $\mathrm{x}$ & & & & & & & & & & & & \\
\hline & Feijão de Cacho & & & & & & & & & & & & & & & & & & \\
\hline & Feijão Estendedor & $\mathrm{x}$ & $\mathrm{x}$ & & & & & & & & & & & & & & & & \\
\hline : & Feijão Faveta & & & & & & & $\mathrm{x}$ & $\mathrm{x}$ & & & & & & & & & & \\
\hline : & Feijão Gandhu & & & & & & & & & & & & & $\mathrm{x}$ & $\mathrm{x}$ & & $\mathrm{x}$ & & $\mathrm{x}$ \\
\hline 2 & Feijão Gordo & & & & & & & & & & & & & $\mathrm{x}$ & $\mathrm{x}$ & & $\mathrm{x}$ & & \\
\hline & Feijão Macassar & $\mathrm{x}$ & $\mathrm{x}$ & & & & & $\mathrm{x}$ & $\mathrm{x}$ & & & & & & & & & & \\
\hline & Feijão Macassar Rosa & $\bar{x}$ & $\mathrm{x}$ & & & & & $\mathrm{x}$ & $\mathrm{x}$ & & & & & & & & & & \\
\hline & $\begin{array}{c}\text { Feijão Macassar Sempre } \\
\text { Verde }\end{array}$ & & & & & & & $\mathrm{x}$ & $\mathrm{x}$ & & & & & & & & & & \\
\hline & Feijão Mulatinho & $\mathrm{x}$ & $\mathrm{x}$ & & & & & $\mathrm{x}$ & $\mathrm{x}$ & & & & & & & & & & \\
\hline & Feijão Ovo de Rolinha & & & & & & & $\mathrm{x}$ & $\mathrm{x}$ & & & & & & & & & & \\
\hline & Feijão Preto & $\mathrm{x}$ & $\mathrm{x}$ & & & & $\mathrm{x}$ & $x$ & $\mathrm{x}$ & & & & & & & & & & \\
\hline & Feijão Rabo de Tatu & & & & & & & & & & & & & & & & & & \\
\hline & Feijão Rosinha & & & & & & & $\mathrm{x}$ & $\mathrm{x}$ & & & & & & & & & & \\
\hline & Jerimum & & & & & & & $\mathrm{x}$ & $\mathrm{x}$ & & & & & $\mathrm{x}$ & $\mathrm{x}$ & & & & \\
\hline & Macaxeira & $\mathrm{x}$ & $\mathrm{X}$ & & & & & $\mathrm{x}$ & $\mathrm{x}$ & & & & & & & & & & \\
\hline & Mandioca & & & & & & & $\bar{x}$ & $\mathrm{x}$ & & & & & & & & & & \\
\hline & Milho Jabatão & $\mathrm{x}$ & $\mathrm{x}$ & $\mathrm{x}$ & & & & $\mathrm{x}$ & $\mathrm{x}$ & & & & & $\mathrm{x}$ & $\mathrm{x}$ & & & & \\
\hline & Abobrinha & $\bar{x}$ & $\mathrm{x}$ & & & & $\mathrm{x}$ & $\mathrm{x}$ & $\mathrm{x}$ & & & & & $\mathrm{x}$ & $\mathrm{x}$ & & & & \\
\hline 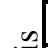 & Açafrão & & & & & & $\mathrm{x}$ & $\mathrm{x}$ & $\mathrm{x}$ & & & & & $\mathrm{x}$ & $\mathrm{x}$ & & & & \\
\hline : స్త్ర & Alface & $\mathrm{x}$ & $\mathrm{X}$ & & & & $\mathrm{x}$ & $\mathrm{x}$ & $\mathrm{x}$ & & & & & & & & & & \\
\hline 氺 & Cebola & & & & & & & $\mathrm{x}$ & $\mathrm{x}$ & & & & & $\mathrm{x}$ & $\mathrm{x}$ & & & & \\
\hline 4 & Cebolinha & $\mathrm{x}$ & $\mathrm{x}$ & & & & $\mathrm{x}$ & $\mathrm{x}$ & $\mathrm{x}$ & & & & & & & & & & \\
\hline & Coentro & $x$ & $\mathrm{x}$ & & & & $\mathrm{x}$ & $x$ & $\mathrm{x}$ & & & & & & & & & & \\
\hline
\end{tabular}




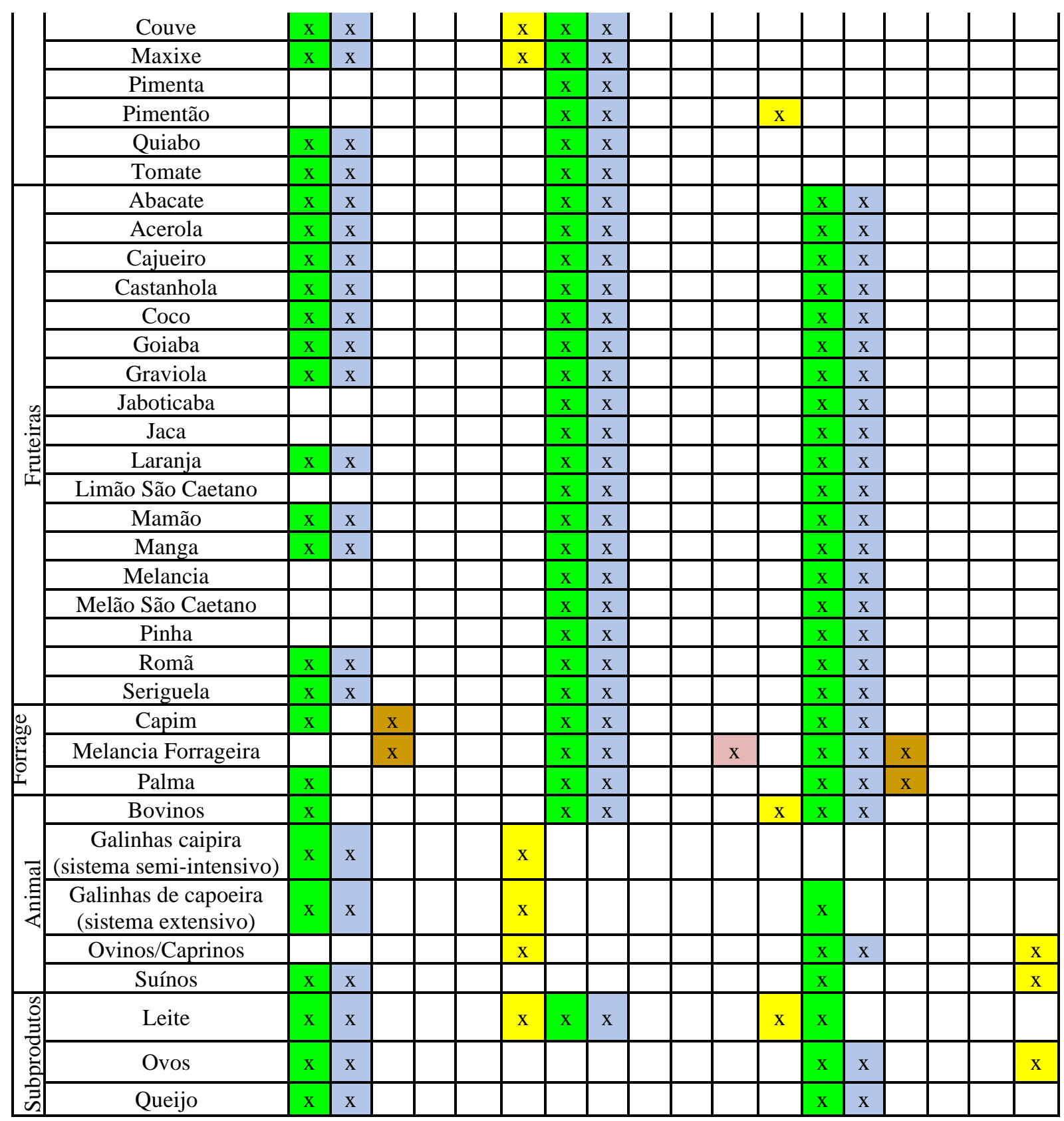

Legenda: PR - produção; $\mathrm{CF}$ - consumo familiar; $\mathrm{CA}$ - consumo animal; $\mathrm{E}$ - estoque; $\mathrm{D} / \mathrm{T}$ - doações/trocas; $\mathrm{CO}$ - comercialização. Fonte: Elaboração própria com base nos dados da pesquisa.

No que se refere ao período, escolha de variedades e volume dos plantios, o início das chuvas conjuntamente com a expectativa do inverno prevista pelos agricultores são fatores determinantes. Isso indica que a pluviosidade tem relação direta com a produção e a rentabilidade, dado que as propriedades dos agricultores não possuem sistemas de irrigação.

Cabe destacar, que a região vem enfrentando um período ininterrupto de oito anos de estiagem e, no ano de 2019, os agricultores encararam fenômenos ludibriados da natureza, ou seja, sinais equivocados de períodos chuvosos, que induziam a decisões para o cultivo de determinada variedade de semente adaptada ao período. Essas distorções persistiram, ocasionando mais de três ciclos produtivos no ano, de modo que as consequências foram perdas significativas de sementes, de insumos e de produção.

Para se preservarem os recursos hídricos e se enfrentarem os desafios dos contrastes ambientais da região, são utilizadas estratégias agroecológicas, envolvendo manejo de água, manejo de solo, manejo das sementes, manejo dos rebanhos e mediadores. Detalhando-se as estratégias similares nos agroecossistemas, há as cisternas calçadão, a cerca viva, os plantios 
em consórcios, os bancos de sementes familiares (BSF), a seleção das melhores sementes e o estoque de forragem (quando existe criação de bovinos), destacando-se, ainda, as sedes de bancos de sementes comunitários (BSC) existentes em dois dos agroecossitemas estudados. O conjunto identificado de estratégias técnicas agroecológicas (manejo da água/solo/sementes/rebanhos e mediadores) e as estratégias de comercialização são apresentadas no Quadro 3 a seguir.

Quadro 3 - Estratégias técnicas agroecológicas e de comercialização.

\begin{tabular}{|c|c|c|c|c|}
\hline \multicolumn{2}{|c|}{ Técnicas Agroecológicas e Comerciais nos Agroecossistemas } & \multirow[t]{2}{*}{ Agro 1} & \multirow[t]{2}{*}{ Agro 2} & \multirow[t]{2}{*}{ Agro 3} \\
\hline \multirow{10}{*}{$\begin{array}{c}\text { Manejo de Recursos } \\
\text { Hidrícos }\end{array}$} & Água de reuso & & & \\
\hline & Barragem subterrânea & & & \\
\hline & Barreiro & $\mathrm{X}$ & $\mathrm{X}$ & \\
\hline & Barreiro trincheira & & $\mathrm{X}$ & \\
\hline & Cacimba & & $\mathrm{X}$ & \\
\hline & Cisterna calçadão & $\mathrm{X}$ & $\mathrm{X}$ & $\mathrm{X}$ \\
\hline & Cisterna enxurrada & & & \\
\hline & Cisterna de placas & $\mathrm{X}$ & $\mathrm{X}$ & $\mathrm{X}$ \\
\hline & Poço artesiano & & & \\
\hline & Tanque de pedra & & & $\mathrm{X}$ \\
\hline \multirow{11}{*}{ Manejo de Solo } & Adubação orgânica & & & \\
\hline & Aplicação de pó de rocha ou MB-4 & & & \\
\hline & Barramento de pedras & & & \\
\hline & Cobertura morta & & $\mathrm{X}$ & \\
\hline & Biofertilizantes & & & \\
\hline & Consórcios & $\mathrm{X}$ & $\mathrm{X}$ & $\mathrm{X}$ \\
\hline & Esterco curtido (esterqueira) & $\mathrm{X}$ & $\mathrm{X}$ & \\
\hline & Controle biológico & & & \\
\hline & Esterco in natura & & & $X$ \\
\hline & Plantio em curva de nível & & & \\
\hline & Rotação de cultura & $\mathrm{X}$ & $\mathrm{X}$ & $\mathrm{X}$ \\
\hline \multirow{8}{*}{$\begin{array}{l}\text { Manejo de } \\
\text { Sementes }\end{array}$} & Bancos de sementes comunitários & & $\mathrm{X}$ & $\mathrm{X}$ \\
\hline & Bancos de sementes familiares & $\mathrm{X}$ & $X$ & $\mathrm{X}$ \\
\hline & Câmara frigorífica & & & \\
\hline & Aquisição de sementes de origem conhecida & $\mathrm{X}$ & $\mathrm{X}$ & $\mathrm{X}$ \\
\hline & Campo de multiplicação de sementes & & & \\
\hline & Ensaios comparados de sementes & $\mathrm{X}$ & & \\
\hline & Seleção das melhores sementes & $\mathrm{X}$ & $\mathrm{X}$ & $\mathrm{X}$ \\
\hline & Uso de produtos naturais para conservação & & & \\
\hline \multirow{5}{*}{$\begin{array}{l}\text { Manejo de } \\
\text { Rebanhos }\end{array}$} & Animais adaptados às condições locais & & & \\
\hline & Estoque de forragem & $\mathrm{X}$ & & $\mathrm{X}$ \\
\hline & Estoque de feno & & & \\
\hline & Mutirões para estoque de forragem & & & \\
\hline & Campo de palma & $\mathrm{X}$ & $\mathrm{X}$ & $\mathrm{X}$ \\
\hline \multirow{9}{*}{$\begin{array}{c}\text { Mediadores } \\
\text { das Técnicas } \\
\text { Agroecológicas }\end{array}$} & Biodigestor & $\mathrm{X}$ & & \\
\hline & Boi de trabalho & $\mathrm{X}$ & & $\mathrm{X}$ \\
\hline & Cultivador & & & \\
\hline & Esterqueira & $\mathrm{X}$ & $\mathrm{X}$ & \\
\hline & Máquina de plantar sementes & & & \\
\hline & Máquina forrageira & $\mathrm{X}$ & & $\mathrm{X}$ \\
\hline & Cerca viva & $\mathrm{X}$ & $\mathrm{X}$ & $\mathrm{X}$ \\
\hline & Motor bomba & $\mathrm{X}$ & & \\
\hline & Uso de equipamentos coletivos (enfardadeira e forrageiras) & & & \\
\hline \multirow{6}{*}{$\begin{array}{c}\text { Canais de } \\
\text { Comercialização }\end{array}$} & Associação & & $\mathrm{X}$ & $\mathrm{X}$ \\
\hline & Atravessador & $\mathrm{X}$ & & $\mathrm{X}$ \\
\hline & Direta ao consumidor & $\mathrm{X}$ & $\mathrm{X}$ & $\mathrm{X}$ \\
\hline & Feira agroecológica & & $\mathrm{X}$ & \\
\hline & Feira livre & & & \\
\hline & Institucional & $\mathrm{X}$ & & \\
\hline
\end{tabular}

Fonte: Elaboração própria com base nos dados da pesquisa. 
No Quadro 3, identificam-se as características distintas dos três estudos de caso (Agros 1, 2 e 3), de modo a evidenciar que cada agroecossistema é singular na dinâmica do conjunto de estratégias técnicas agroecológicas e comerciais. Enquanto o Agro 1 diversifica as técnicas agroecológicas, o Agro 2 explora as diversidades de manejo de recursos hídricos e, distintamente, o Agro 3 não se centraliza em nenhuma estratégia, mas se diversifica no conjunto de técnicas e comercialização.

Enfim, a partir da contextualização, pode-se compreender o funcionamento da produção familiar de base agroecológica, entendendo-se seus fluxos (insumos, produtos e renda). A partir de uma visão holística, obtém-se o êxito na compreensão da agricultura familiar, ou seja, entende-se o todo, desde seus componentes até as suas relações (Solis \& Rivera, 2018). Desse modo, infere-se a complexidade desses sistemas nos aspectos metodológicos e organizacionais, ressaltando-se suas características singulares.

Além disso, destacam-se as dificuldades enfrentadas no período analisado, devido a certos fenômenos ambientais, fato que impactou diretamente no desempenho produtivo e, consequentemente, na subsistência dos agroecossistemas. Entretanto, evidenciam-se a persistência e a nobreza dos agricultores que responderam a essa situação, valendo-se de diferentes estratégias e resistiram, desenvolvendo uma agricultura sustentável.

\subsection{Evidências do Desempenho Socioeconômico}

Para analisar o desempenho socioeconômico, inicia-se a análise, explorando-se a composição dos agroecossistemas, especificamente no que diz respeito aos indicadores sociais. Foram observadas distinções entre os núcleos familiares (Ver Tabela 1), considerando-se o quantitativo de pessoas dependentes de cada agroecossistema, assim como os gêneros e as faixas etárias. Cabe explicar que, conforme demonstrado na Tabela 1, as crianças não estão categorizadas por gênero, diferentemente dos idosos, que estão incluídos na classificação por gênero (homem/mulher).

Tabela 1 - Composição do núcleo familiar.

\begin{tabular}{llllllllll}
\hline \multirow{2}{*}{ Agroecossistema } & \multirow{2}{*}{$\begin{array}{l}\text { Componentes } \\
\text { Familiares }\end{array}$} & \multicolumn{2}{c}{ Homens } & \multicolumn{2}{c}{ Mulheres } & \multicolumn{2}{c}{ Idosos } & \multicolumn{2}{c}{ Crianças } \\
\cline { 3 - 9 } & f & $\%$ & $\mathrm{f}$ & $\%$ & $\mathrm{f}$ & $\%$ & $\mathrm{f}$ & $\%$ \\
\hline Agro 1 & 6 & 2 & $33 \%$ & 3 & $50 \%$ & - & - & 1 & $17 \%$ \\
Agro 2 & 3 & 1 & $33 \%$ & 2 & $67 \%$ & 2 & $67 \%$ & - & - \\
Agro 3 & 10 & 2 & $20 \%$ & 3 & $30 \%$ & 1 & $10 \%$ & 5 & $50 \%$ \\
\hline
\end{tabular}

Legenda: $\mathrm{f}$ = frequência ou quantidade de vezes em que o mesmo dado aparece em um conjunto (no caso em questão, a quantidade de vezes em que homem, mulher, criança e/ou idoso aparece em cada Agro). Fonte: Elaboração própria com base nos dados da pesquisa.

Considerando-se apenas a força de trabalho, ou seja, os componentes familiares maiores de 18 anos, o Agro 1 é constituído por pessoas entre 23 e 56 anos; o Agro 2, entre 45 e 86 anos; e o Agro 3, entre 18 e 54 anos. Denota-se que o Agro 1 é composto por um núcleo familiar mais jovem: dentre os seus componentes, 3 estão entre 23 e 25 anos e nenhum componente nesse grupo é considerado idoso, maior de 60 anos, conforme classificação da Organização Mundial da Saúde (OMS) (SBGG, 2015), distintamente ao que ocorre no caso do Agro 2, em que 67\% dos seus componentes são idosos.

Quanto ao gênero dessa força de trabalho, o predomínio é o sexo feminino, destacando-se o Agro 3, com gestão realizada por uma mulher, diferentemente do Agro 1 e Agro 2, em que as lideranças são do sexo masculino. Dos componentes que representam a força de trabalho dos agroecossistemas, identificou-se uma pessoa analfabeta, sendo esta do sexo feminino e pertencente ao Agro 2, de núcleo familiar com integrantes mais velhos. O fato denota características de uma herança patriarcal e de restrições educacionais da região nordeste do Brasil.

Nessa perspectiva, cita-se que, entre a força de trabalho, nenhum possui grau de instrução superior e, independentemente da idade, não indicaram perspectivas futuras de realização. No total dos agroecossistemas, são três pessoas 
com o nível fundamental completo, uma com nível fundamental incompleto e os demais com ensino médio, situando-se o Agro 3 como o núcleo em que os membros apresentaram o maior grau de instrução, todos com ensino médio, embora um componente ainda se encontre cursando esse nível educacional.

Ressalta-se ainda, nessa força de trabalho, aspectos de trabalho familiar, com número reduzido de pessoas, constituindo-se pelo proprietário, sua esposa e filhos, que auxiliam nas atividades de forma integral ou parcial, de modo que, no período estudado, não houve contratação de mão de obra externa. Distintamente, no Agro 3, as funções agrícolas são desenvolvidas por três herdeiros da propriedade; destes, dois atuam exclusivamente na agricultura. Destacam-se os desafios relatados no Agro 1, para a sucessão da produção rural no agroecossitema, devido aos esforços necessários para se desenvolverem as atividades agrícolas, as quais são desvalorizadas no mercado local, sem proporcionar retorno financeiro justo.

Os esforços podem ser visualizados no quantitativo de horas diárias despendido nas atividades do agroecossistema: no Agro 1, são 40 horas diárias; no Agro 2, 18 horas; e, no Agro 3, 31 horas. Desdobrando-se essa dinâmica, tem-se no Agro 1 uma média de 10 horas diárias de trabalho desempenhado pelos homens e, aproximadamente, 7 horas pelas mulheres. No Agro 2, são em média 6 horas de trabalho por componente familiar e, no Agro 3, aproximadamente 6 horas de trabalho por mulheres e 7 por homens. Desta forma, os relatos do Agro 1 indicam relação com a excessiva carga de trabalho, destacando-se que não existe para esse agroecossitema dia de descanso, dada a criação animal que exige atividades cotidianamente.

Outra observação quanto às horas trabalhadas é a relação com a idade dos agricultores. Essa questão fica evidente no Agro 2, em que se nota um menor número de horas trabalhadas para a maior faixa etária identificada entre os agroecossistemas. Isto pode ser decorrência das atividades agrícolas que exigem grandes esforços físicos, demandando mão-de obra de maior força.

Nas atividades domésticas, a responsabilidade e o desempenho são exclusivos das mulheres, indicando a influência de um modelo de família patriarcal. Além disso, a mão de obra feminina contribui para os cultivos dos quintais, a criação das aves e a produção dos subprodutos, de modo que as mulheres, sazonalmente, aumentam sua carga de trabalho diária, pois é força necessária na época de colheita dos roçados. Destaca-se também a participação atuante dessas mulheres em movimentos sociais, sobressaindo-se a gestora do Agro 2, que tem participação ativa nos eventos.

No Gráfico 1, a seguir, demonstra-se o tempo de ocupação por gênero nos agroecossistemas. O maior período de ocupação é das mulheres, considerando-se que a presença feminina é maioria; além disso, elas desempenham tanto as atividades agrícolas como as atividades domésticas, sendo esta última função indispensável para o funcionamento do agroecossistema.

Gráfico 1 - Tempo de ocupação por gênero no agroecossistema.

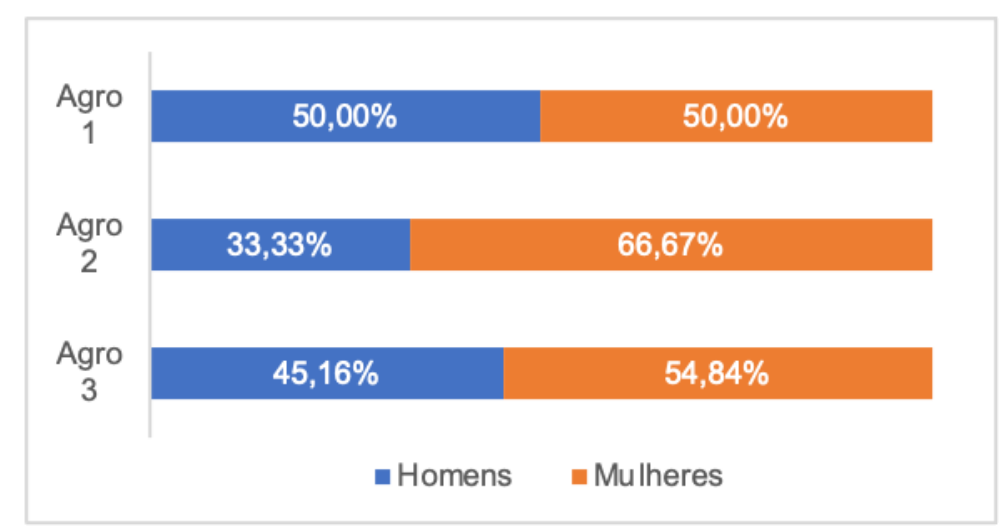

Fonte: Autores. 
Quanto aos indicadores econômicos, observa-se o produto bruto (Ver Gráfico 2), correspondendo a todos os produtos obtidos no agroecossistema para o período estudado (2019), assinalado pelo valor total no Agro 1 de R\$ 47.746,50; no Agro 2, de $\mathrm{R} \$ 4.538,20$; e, no Agro 3, de $\mathrm{R} \$ 9.518,47$. Para os agroecossistemas, o maior valor é representado pelas vendas, correspondendo no Agro 1 a 91\% do produto bruto; consecutivamente, no Agro 3, equivale a 64\%; e, no Agro 1, com menor proporção, a 51\%. Distintamente, para o autoconsumo, o Agro 2 tem a maior proporção, a saber, de $34 \%$, quando comparada à do Agro 3, de 22\%, e à do Agro 1, de 4\%. Para os estoques de produtos, a parcela equivalente ao total do produto bruto é maior no Agro 3, a saber, de 13\%, enquanto no Agro 1 e no Agro 2, igualmente, constitui 4\%.

Gráfico 2 - Produto bruto (em R\$).

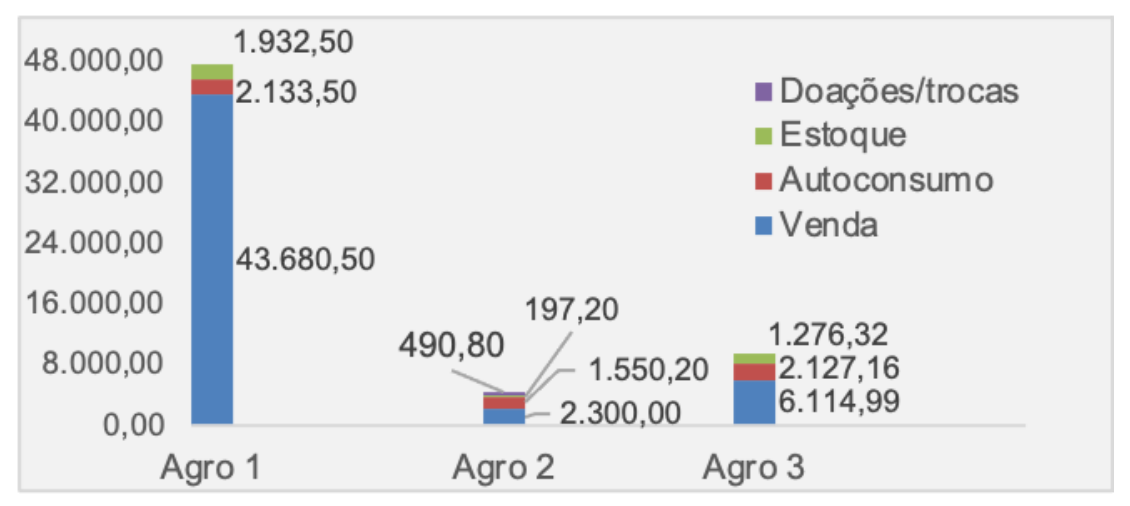

Fonte: Autores.

Cabe mencionar a influência pluviométrica na Paraíba, dada a não existência de sistemas de irrigação nos agroecossistemas. A variação da quantidade de chuvas nos ciclos produtivos é determinante para a produção, de modo que, em um ano de baixo índice pluviométrico, como o período ora analisado, houve um baixo desempenho produtivo, consequentemente, impactando as rendas agrícolas, sendo estas sobretudo provenientes dos itens comercializados.

No Gráfico 3, a seguir, evidenciam-se as origens das rendas, classificadas como agrícolas e não agrícolas.

Gráfico 3 - Origens das rendas (em R\$).

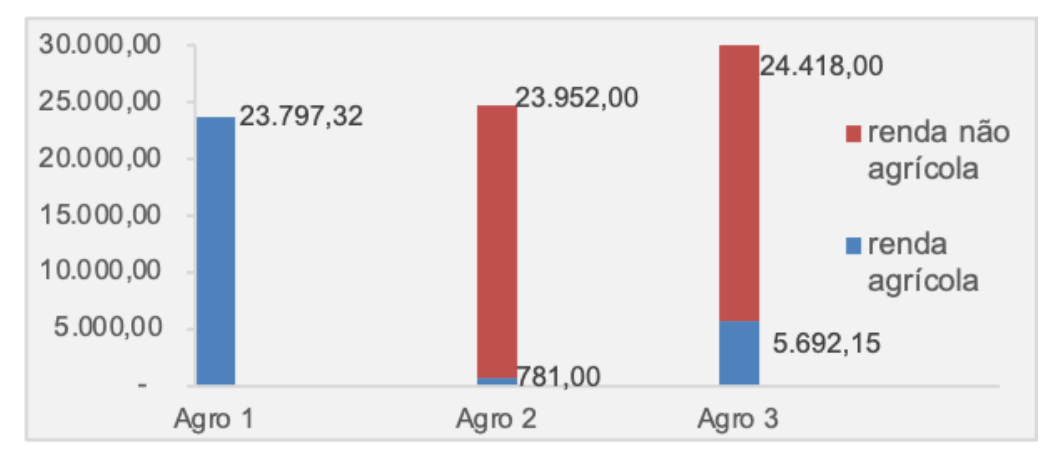

Fonte: Autores.

No Agro 1, têm-se como fonte de renda, exclusivamente, os resultados obtidos do agroecossistema. Descontando-se os custos, obtém-se um valor monetário de $\mathrm{R} \$ 23.797,32$ anualmente, enquanto no Agro 2 a fonte principal de renda monetária são as transferências de rendas (aposentadorias) e, no Agro 3, a renda não agrícola é composta tanto de transferências de rendas, destacando-se, neste caso, a inclusão em programas sociais ( $\mathrm{R} \$ 14.418,00)$, como de pluriatividades ( $\mathrm{R} \$ 10.000,00)$.

Logo, a dependência do agroecossistema, único meio de subsistência para os componentes do Agro 1, impõe buscas de estratégias arrojadas e inovadoras. Desta forma, o seu gestor busca ampliar os nichos de produção, por meio das vendas de 
roçados, horticultura e da produção animal, esforços estes que buscam superar a sazonalidade dos plantios, dispondo de itens durante todo o ano, atendendo ao mercado e gerando capital de giro.

O capital de giro é um obstáculo para os componentes do Agro 1. Sem outros meios de recursos, o gestor opta, predominantemente, por vendas (via atravessadores) que trazem recurso financeiro imediato, porém, com redução nos ganhos, diminuindo-se a rentabilidade do agroecossistema, posto que o indicador de rentabilidade no Agro 1 é de 1,27, comparado ao Agro 3, que é de 2,96, ou seja, para cada 1 real de custo no Agro 2, o retorno é de 1,96, à medida que no Agro 1 se agrega apenas 0,27 . Para se constituir esse indicador, são necessárias informações sobre o valor agregado (Ver Tabela 2) e custos totais de produção (Ver Gráfico 4).

Tabela 2 - Valor agregado.

\begin{tabular}{lccrccc}
\hline Indicadores & & Agro 1 & & Agro 2 & & Agro 3 \\
\hline Vendas & $\mathrm{R} \$$ & $43.680,50$ & $\mathrm{R} \$$ & $2.300,00$ & $\mathrm{R} \$$ & $6.114,99$ \\
Autoconsumo & $\mathrm{R} \$$ & $2.133,50$ & $\mathrm{R} \$$ & $1.550,20$ & $\mathrm{R} \$$ & $2.127,16$ \\
Doações e Trocas & & - & $\mathrm{R} \$$ & 490,80 & & - \\
Custos Intermediários & $-\mathrm{R} \$$ & $17.800,00$ & $-\mathrm{R} \$$ & 820,00 & $-\mathrm{R} \$$ & 706,00 \\
\hline Valor Agregado & $\mathbf{R} \$$ & $\mathbf{2 8 . 0 1 4 , 0 0}$ & $\mathbf{R} \$$ & $\mathbf{3 . 5 2 1 , 0 0}$ & $\mathbf{R} \$$ & $\mathbf{7 . 5 3 6 , 1 5}$ \\
\hline
\end{tabular}

Fonte: Elaboração própria com base nos dados da pesquisa.

No Gráfico 4, além de se apresentar o total dos custos totais consumidos na produção, mensura-se o valor consumido dos recursos que foram obtidos por meio da reciprocidade ecológica. É importante considerar que os agricultores não mantinham registros de custos, de modo que as informações ficavam limitadas às suas percepções.

Gráfico 4 - Custos de produção e reciprocidade ecológica (em R\$).

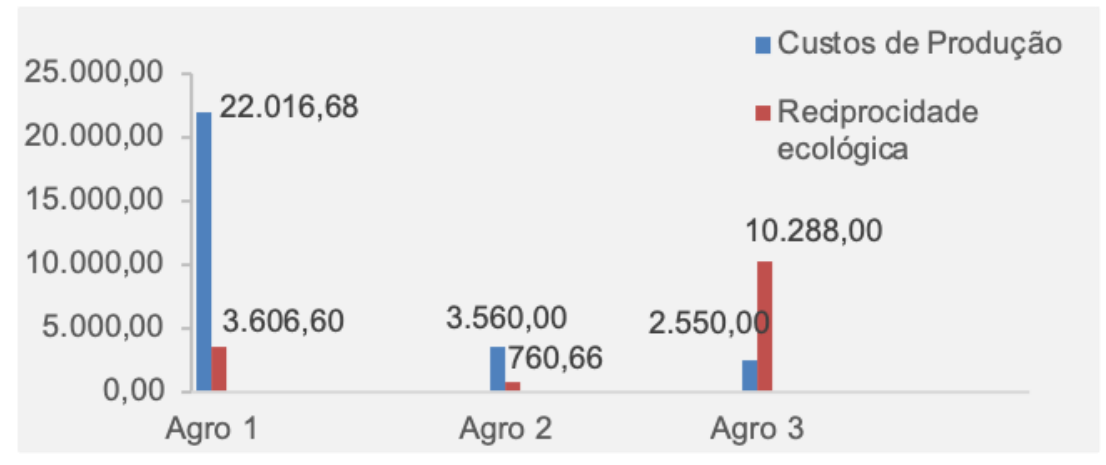

Fonte: Autores.

Em uma perspectiva estratégica, insumos gerados pelo agroecossistema, no caso do Agro 3, são equilibrados com a criação animal, de modo que os recursos gerados no próprio agroecossistema são suficientes para alimentar todos os animais, não havendo custos relevantes com a produção animal. Distintamente, no Agro 1, com quantidade de animais superior, quando comparado aos demais agroecossistemas, os insumos provenientes da reciprocidade ecológica não são suficientes para a alimentação animal, demandando custos mais elevados.

Ademais, observando-se a produção animal, tem-se que o capital vivo (semoventes) no Agro 1 no início de 2019 totalizava $\mathrm{R} \$ 52.470,00$, o qual reduziu no fim do ano para $\mathrm{R} \$ 12.180,00$, enquanto no Agro 3 não houve variação significativa, iniciando com R \$21.400,00 e terminando com R\$20.040,00, e no Agro 2 de R\$120,00 para R\$ 630,00. O capital semovente é utilizado pelos agricultores como uma fonte de investimento, em períodos de pouca colheita, como aconteceu em 2019, no Agro 1, cujos componentes, sem outras fontes de recursos, utilizaram parte desse capital acumulado 
para a subsistência do agroecossistema.

Quanto às reservas de insumos ao final do período, no Agro 3, tem-se em estoque o maior valor de insumos, dentre estes a forragem para a alimentação animal, representando 82\% das reservas; no Agro 1, esse valor se refere aproximadamente a $50 \%$ dos insumos conservados.

Na mensuração dos insumos, incluem-se as sementes conservadas para os plantios posteriores, sendo estas estocadas em bancos de sementes familiares e comunitários. No agro 2 e no Agro 3, as sementes são estocadas tanto no banco familiar como no comunitário, este último com sede nos agroecossistemas, enquanto no Agro 1 se opta pela guarda exclusiva no banco familiar.

Observando-se as variedades de sementes preservadas para os plantios futuros, notam-se diferentes estratégias de gestão entre os agroecossistemas. No Agro 1, reservaram-se 7 variedades de sementes (205 kg); no Agro 2, guardaram-se 13 (58 kg); e, no Agro 3, 9 variedades (107 kg). Enquanto no Agro 1 se priorizam as sementes que atendam os desejos e necessidades do mercado, no Agro 2 e no Agro 3, distintamente, prima-se por diversidade, guardando-se sementes menos comerciais, contribuindo-se, assim, ativamente para a preservação de um patrimônio genético. A associação dos agricultores para utilização dos bancos de sementes comunitários pode influenciar nessa perspectiva de gestão diversificada nos estoques de sementes no Agro 2 e no Agro 3.

Finalmente, o pequeno retorno financeiro indica que os agricultores precisam de uma estrutura econômica para alavancarem os agroecossistemas. Como Hilmi (2019) afirmou, o grande obstáculo para se desenvolver uma agricultura sustentável é a falta de apoio financeiro à agricultura familiar. Essa afirmação é complementada por Nogueira et al. (2019), que conclui que os principais desafios dos pequenos agricultores envolvem aspectos sociais e econômicos, destacando-se a assistência técnica e a cadeia de mercado.

Acredita-se que a implementação de políticas intersetoriais, a partir de aportes financeiros, direcionados para programas de apoio à comercialização e capacitações dos agricultores na gestão do empreendimento familiar, torna-se um caminho promissor para o desenvolvimento de uma agricultura de base agroecológica. Concorda-se, portanto, com o argumento de Soldi et al. (2019), quanto à necessidade de uma reforma na política agrícola com vista a beneficiar as produções sustentáveis, e com o que é constatado nos estudos de Valencia et al. (2019), que sustentam que políticas públicas criam suporte de mercado, favorecem a resiliência do sistema alimentar e contribuem para a autonomia dos agricultores familiares.

Além disso, argumenta-se que uma alternativa para a não dependência de políticas públicas seria a organização em forma de cooperativa de crédito, com vistas a promover soluções financeiras e ser instrumento de incentivo e desenvolvimento econômico e social para os agricultores. Embora não tenham sido encontradas evidências explícitas que enfatizam essa afirmação, Nogueira et al. (2019) refletem sobre a combinação de estratégias para promover a autossuficiência de comunidade agrícolas, e Williams et al. (2018) complementam que a articulação de estruturas governamentais, de organização social e de institucionais apropriadas contribuem para potencializar o desenvolvimento de sistemas alimentares agroecológicos.

\subsection{Estratégias de Subsistência}

Nesta seção, busca-se sistematizar as dinâmicas estratégicas para subsistência, as quais foram evidenciadas e analisadas a partir da composição dos capitais e da diversificação, conforme expostas no Quadro 2, apresentado acima, e na Tabela 3, apresentada a seguir.

No Agro 1, cultivaram-se 12 variedades de sementes no roçado e 8 variedades nos quintais; identificou-se também a criação de bovinos, suínos e aves. Da sua produção, houve comercialização de 7 variedades (1225 kg) do roçado, todas as variedades disponíveis dos quintais (horticultura) e da produção animal, assim como 1 dos seus subprodutos. Dessas vendas, $65 \%$ foram para atravessadores, $30 \%$ realizadas de forma institucional (programas públicos) e $5 \%$ realizadas diretamente ao 
consumidor.

No Agro 2, cultivaram-se nos roçados 21 variedades de sementes, 12 variedades nos quintais e criação de aves (galinha de capoeira). Desta produção, destinou-se para comercialização 1 (uma) variedade (40 kg) do roçado, 1 (uma) do quintal, as aves e um dos seus subprodutos. Essas vendas foram excedentes do consumo familiar, das quais $80 \%$ foram transacionadas no mercado por meio da assessoria da AS-PTA, e os demais $20 \%$ foram por meio de feiras agroecológicas e para o consumidor direto.

No Agro 3, foram cultivadas 12 variedades de sementes; os quintais foram destinados apenas para o consumo familiar; e, da produção animal, identificaram-se bovinos, aves (galinha de capoeira), suínos, caprinos e ovinos. O escoamento por meio da comercialização foi de 3 variedades do roçado (522 kg) e, da produção animal (suínos e caprinos/ovinos), destas vendas, $90 \%$ foi assessorada pela AS-PTA e os 10\% restantes para atravessadores e vendas diretas.

Outros aspectos observados são a diversidade da alimentação familiar e as características culinárias com significado cultural. A maior parte dos alimentos consumidos pelo núcleo familiar é produzido no próprio agroecossistema, uma fonte de diversidade alimentar, incluindo-se variedades de vegetais, frutas e proteína animal, o que reforça o que foi constatado nos estudos de Kangmennaang et al. (2017), Batista e Oliveira (2018) e Lucantoni et al. (2018), a saber, que a estratégia agroecológica de diversificação de culturas contribue positivamente para a segurança e soberania alimentar das famílias.

A partir da abordagem das dimensões de estratégias de subsistência, conforme descrita na literatura (Barrett \& Swallow, 2004; Bebbington, 1999); Ellis, 2000; Krantz, 2001), expõem-se a seguir as dimensões de capitais e variáveis usadas para a análise dessas estratégias (Ver Tabela 3). Ressalta-se que as informações apresentadas na Tabela 3 referem-se a valores mensurados no final do ciclo econômico de 2019. 
Tabela 3 - Composição dos capitais.

\begin{tabular}{|c|c|c|c|}
\hline Dimensões de Estratégias de Subsistência & AGRO 1 & AGRO 2 & AGRO 3 \\
\hline \multicolumn{4}{|l|}{ Indicadores } \\
\hline \multicolumn{4}{|l|}{ Capital Humano } \\
\hline Idade do gestor & 56 & 84 & 56 \\
\hline Tempo de escola (anos) & 6 & 8 & 11 \\
\hline $\begin{array}{l}\text { Indivíduos com trabalhos não agrícolas } \\
(\%)\end{array}$ & 0 & 0 & 1 \\
\hline Razão de sexo (H/M) & 0,67 & 0,50 & 0,67 \\
\hline Mão de obra paga & 0 & 0 & 0 \\
\hline \multicolumn{4}{|l|}{ Capital Físico } \\
\hline Tamanho da propriedade (hectares) & 8 & 14,5 & 7,25 \\
\hline Cisternas & 3 & 1 & 2 \\
\hline \multicolumn{4}{|l|}{ Capital Financeiro } \\
\hline Renda familiar (anual) (R\$) & $23.797,00$ & $24.733,00$ & $30.110,00$ \\
\hline Renda agrícola & $100 \%$ & $3 \%$ & $19 \%$ \\
\hline Transferências de renda (\%) & 0 & $97 \%$ & $48 \%$ \\
\hline Pluriatividade & 0 & 0 & $33 \%$ \\
\hline Renda per capita (mensal) $(\mathrm{R} \$)$ & 331,00 & 687,00 & 228,00 \\
\hline \multicolumn{4}{|l|}{ Capital Natural } \\
\hline Produção animal (quantidades) & 31 & 21 & 49 \\
\hline Bovinos & 3 & 0 & 6 \\
\hline Suínos & 6 & 0 & 9 \\
\hline Aves & 22 & 21 & 33 \\
\hline Caprinos/Ovinos & 0 & 0 & 1 \\
\hline \multicolumn{4}{|l|}{ Produção vegetal } \\
\hline $\begin{array}{l}\text { Estoque de produtos } \\
\text { (variedade/quantidade) }\end{array}$ & $4 / 630 \mathrm{~kg}$ & $2 / 36 \mathrm{~kg}$ & $6 / 367 \mathrm{~kg}$ \\
\hline $\begin{array}{l}\text { Estoque de sementes } \\
\text { (variedade/quantidade) }\end{array}$ & $7 / 205 \mathrm{~kg}$ & $13 / 58 \mathrm{Kg}$ & 9/107 kg \\
\hline Silagem (quantidade - toneladas) & 1 & 0 & 2,5 \\
\hline \multicolumn{4}{|l|}{ Capital Social } \\
\hline $\begin{array}{l}\text { Propriedade rural com múltiplos } \\
\text { domicílios } \\
\text { Tempo de participação social }\end{array}$ & Não & Sim & Sim \\
\hline (horas/anual) & 18 & 90 & 80 \\
\hline Representante da comunidade & Não & Sim & Sim \\
\hline
\end{tabular}

Fonte: Elaboração própria com base nos dados da pesquisa.

A partir das estratégias de subsistências sistematizadas na Tabela 3 acima e com os desdobramentos socioeconômicos apresentados, pode-se traçar o perfil dos agroecossistemas.

O perfil do Agro 1 ficou caracterizado pela disponibilidade de capital físico e natural (principalmente criação de aves), com pouca influência social. O capital humano é jovem, o qual sobrevive unicamente do trabalho desenvolvido no agroecossitema, ou seja, única fonte de renda. Desse modo, denota-se um melhor desempenho no esforço de atender o mercado, distribuindo sua força de trabalho conforme as oportunidades que lhe conferem maior capital de giro, embora com menor rentabilidade, propiciando ao agroecossistema características determinantes de um empreendimento.

O Agro 2, por sua vez, ficou caracterizado por expôr a maior renda per capita, exibe uma relação de interdependência entre o seu perfil e o posicionamento de mercado e suas estratégias são moldadas a partir do processo de interação social. Nele existe a disponibilidade de capital financeiro, e as estratégias de subsistência assumem uma forte característica cultural, sem considerar a demanda do mercado, de modo que os cultivos são orientados para a diversificação, a preservação das variedades das sementes crioulas e a alimentação familiar. Ademais, o capital humano é mínimo nesse agroecossistema, sendo o gestor caracterizado como idoso. Convém esclarecer que o capital físico, disponível em termos de área, agrega mais 8 (oito) domicílios, compostos por parentes próximos ao núcleo familiar que compôs o Agro 2 para fins desta pesquisa, mas cada um desses domicílios contém o seu próprio núcleo familiar, assim como o seu agroecossistema constituído. 
No Agro 3, outra abordagem de estratégia de subsistência é adotada, de modo que são estocadas e cultivadas em maior quantidade as variedades de sementes que atendem a demanda do mercado local e, em número menor, as variedades peculiares, sendo estas orientadas para o autoconsumo e preservação. O capital social também é uma característica predominante, assim como a disponibilidade de capital humano jovem, com liderança exercida por uma mulher. Tanto o capital financeiro como o capital natural são diversificados, sendo este último, especificamente, o de produção animal, ponderado a partir da capacidade reprodutiva do agroecossistema. Comparado aos demais, este componente familiar alcançou um maior retorno financeiro, embora tenha a menor renda per capita, dado o número total de pessoas dependendo do agroecossistema.

A descrição dos perfis sugere caminhos diferentes, com consequências diretas na subsistência dos agroecossistemas, mas, em comum, estão enraizados na lógica agroecológica. Enfim, inferem-se dificuldades em prever um perfil típico de estratégia de subsistência, mas conclui-se que há uma relação intrínseca entre indicadores socioeconômico e as estratégias de subsistência adotadas. A partir de estudos socioeconômicos, ações pontuais podem ser realizadas para possibilitar o desenvolvimento de uma agricultura sustentável, de forma a ampliar oportunidades nos aspectos econômicos e sociais aos agricultores familiares.

Nesse contexto, as alternativas que buscam compreender dentro de um sistema holístico as variáveis que são relevantes tornam-se um meio promissor (Nicolay, 2019). Evidenciar às estruturas governamentais e às organizações não governamentais quanto à relevância de considerarem os indicadores socioeconômicos nos seus direcionamentos pode levar a uma prosperidade compartilhada.

\section{Conclusão}

Valendo-se da literatura e de três estudos de caso, neste trabalho, buscou-se avaliar aspectos ligados ao desempenho da agricultura familiar agroecológica aplicados em um contexto brasileiro. Singularmente, neste artigo, exploraram-se o desdobramento de indicadores socioeconômicos e a adoção de estratégias de subsistência, delineando-se os agroecossistemas envolvidos.

Ressaltam-se a diversidade e as características singulares identificadas em cada agroecossistema, evidenciando-se a unicidade dos sistemas agroecológicos. A gestão determinada pelo contexto socioeconômico revela que indicadores como a composição das rendas, formação familiar, disponibilidade de força de trabalho são norteadores das decisões dos agricultores.

Além disso evidenciou-se a relevância de alavancar monetariamente os pequenos agricultores, como forma de fortalecer o desenvolvimento de uma agricultura familiar na ótica agroecológica. A partir de políticas públicas e transferência de renda, é possível construir sistemas agrícolas mais sustentáveis, equilibrando-se a utilização do capital natural e viabilizando-se uma alternativa de produção agrícola mais sustentável.

As abordagens baseadas em indicadores socioeconômicos, por sua vez, revelaram capacidade para se capturarem as variações dentro dos sistemas de agricultura familiar de base agroecológica. A partir da contextualização dos agroecossistemas e, simultaneamente, da compreensão dos indicadores socioeconômicos, foi possível entender a realidade dos agricultores, de modo a indicar quais os recursos financeiros, humanos, físicos, naturais e sociais estavam disponíveis para os agricultores realizarem suas atividades, tendo em vista a geração de renda para a sua subsistência.

Complementando-se esses resultados, pode-se afirmar que a sistematização dos recursos utilizados, em termos de capitais financeiros, humanos, físicos, naturais e sociais, foi fundamental para se entenderem as estratégias de subsistência adotadas. De modo mais específico, permitiu o entendimento de um contexto brasileiro de agricultura familiar de base agroecológica que possui poucos recursos, mas que, com o que tem disponível, dinamiza as estratégias de subsistência e busca equilibrar as funções ambientais, sociais e econômicas. Desse modo, cada agroecossistema, considerando-se a subsistência 
familiar e as suas restrições, atua para proteger os recursos naturais.

Nesse sentido, compreender a realidade dos agricultores familiares, considerando-se os seus indicadores socioeconômicos e as dinâmicas estratégicas de subsistência, é um caminho para se viabilizar a prática de uma produção agrícola sustentável, direcionando-se, de forma eficiente, políticas e projetos que apoiem uma alternativa sustentável para a produção agrícola e beneficiando um sistema alimentar que favorece simultaneamente a soberania e a segurança, a cultura regional, o meio ambiente e o desenvolvimento da economia local.

Neste trabalho, limita-se a discussão à abordagem de três casos, considerando-se apenas um ano de seca, fato que dificulta uma generalização dos resultados, embora estes tenham sido apoiados por uma equipe multidisciplinar, envolvendo a participação ativa dos agricultores. Diante disso, pesquisas futuras longitudinais e envolvendo um maior número de casos para discussão dos indicadores socioeconômicos e das estratégias de subsistência têm potencial para agregar positivamente conhecimento sobre o tema. Outra sugestão de estudo para ser desenvolvido é uma análise da inter-relação entre os indicadores socioeconômicos e as estratégias de subsistência, de modo a se compreenderem as relações de independência.

\section{Agradecimentos}

Este projeto foi apoiado pelo financiamento de uma Bolsa da Coordenação de Aperfeiçoamento de Pessoal de Nível Superior - CAPES e uma Bolsa de IC-CNPq, IC-PROPESQ-UFPB.

\section{Referências}

Altieri, M. A., Funes-Monzote, F. R., \& Petersen, P. (2012). Agroecologically efficient agricultural systems for smallholder farmers: Contributions to food sovereignty. Agronomy for Sustainable Development, 32(1), 1-13.

Altieri, M. A., \& Nicholls, C. I. (2017). The adaptation and mitigation potential of traditional agriculture in a changing climate. Climatic Change, 140(1), 3345 .

Altieri, M. A., Nicholls, C. I., Henao, A., \& Lana, M. A. (2015). Agroecology and the design of climate change-resilient farming systems. Agronomy for Sustainable Development, 35, 869-890. https://link.springer.com/article/10.1007/s13593-015-0285-2

Araújo, A. L. de, Oliveira, R. T. de, Ferreira, T. O., Romero, R. E., \& Oliveira, T. S. de. (2013). Evaluation of soil structure using participatory methods in the semiarid region of Brazil. Rev. Ciênc. Agron., 44(3), 411-418. https://doi.org/10.1590/S1806-66902013000300001

Barrett, C., \& Swallow, B. M. (2004). Dynamic Poverty Traps and Rural Livelihoods. In: Ellis, F. \& Freeman, H. A. de (Editors). Rural Livelihoods and Poverty Reduction Policies. London: Routledge.

Batista, M. A. da S., \& Oliveira, A. M. de. (2018). A transição agroecológica na produção camponesa. Boletim Goiano de Geografia, 38(3), 534-550.

Bebbington, A. (1999). Capitals and capabilities: a framework for analyzing peasant viability, rural livelihoods and poverty. World Development, 27(12), 2021-2044.

Bezerra, L. P., Franco, F. S., Souza-Esquerdo, V. F., \& Borsatto, R. (2018). Participatory construction in agroforestry systems in family farming: ways for the agroecological transition in Brazil. Agroecology and Sustainable Food Systems, 43(2), 180-200. https://doi.org/10.1080/21683565.2018.1509167

Bolfe, É. L. (Coord.). (2018). Visão 2030: o futuro da agricultura brasileira. Brasília: Embrapa, 212. https://www.embrapa.br/documents/10180/9543845/Visão+2030+-+o+futuro+da+agricultura+brasileira/2a9a0f27-0ead-991a-8cbf-af8e89d62829?version=1.1

Capellesso, A. J., Cazella, A. A., Schmitt Filho, A. L., Farley, J., \& Martins, D. A. (2016). Economic and environmental impacts of production intensification in agriculture: comparing transgenic, conventional, and agroecological maize crops. Agroecology and Sustainable Food Systems, 40(3), 215-236. https://www.tandfonline.com/doi/abs/10.1080/21683565.2015.1128508

Cochet, H. (2015). Controverses sur l'efficacité économique des agricultures familiales: indicateurs pour une comparaison rigoureuse avec d'autres agricultures. Revue Tiers Monde, Armand Colin (Éd.). Agricultures familiales : trajectoires, modernités et controverses (II), 221. https://www.cairn.info/revuetiers-monde-2015-1-page-9.htm

D’Annolfo, R., Gemmill-Herren, B., Graeub, B., \& Garibaldi, L. A. (2017). A review of social and economic performance of agroecology. International Journal of Agricultural Sustainability, 15, 632-644. https://www.tandfonline.com/doi/abs/10.1080/14735903.2017.1398123

Dalsgaard, J. P. T. (1997). A Quantitative Approach for Assessing the Productive Performance and Ecological Contributions of Smallholder Farms. Agricultural Systems, 55(4), 503-533. https://doi.org/10.1016/S0308-521X(97)00022-X 
Díez, L., Cussó, X., Padró, R., Marco, I., Cattaneo, C., Olarieta, J. R., Garrabou, R., \& Tello, E. (2018). More than energy transformations: a historical transition from organic to industrialized farm systems in a Mediterranean village (Les Oluges, Catalonia, 1860-1959-1999). International Journal of Agricultural Sustainability, 16(4-5), 399-417. https://doi.org/10.1080/14735903.2018.1520382

Dumont, B., Groot, J. C. J., \& Tichit, M. (2018). Review: make ruminants green again - how can sustainable intensification and agroecology converge for a better future? Animal, 12(2), 210-219.

Eisenhardt, K. M., \& Graebner, M. E. (2007). Theory building from cases: opportunities and challenges. Revista da Academia de Gestão, 50(1), 25-32.

Ellis, F. (2000). The determinants of rural livelihood diversification in developing countries. Journal of Agricultural Economics, 51(2), 289-302.

Emeana, E. M., Trenchard, L., Dehnen-Schmutz, K., \& Shaikh, S. (2018). Evaluating the role of public agricultural extension and advisory services in promoting agro-ecology transition in Southeast Nigeria. Agroecology and Sustainable Food Systems, 43(2), 123-144. https://doi.org/10.1080/21683565.2018.1509410

Nogueira, R. F., Roitman, I., Carvalho, F. A., \& Soldati, G. T. (2019). Challenges for agroecological and organic management of Cabruca cocoa agroecosystems in three rural settlements in south Bahia, Brazil: perceptions from local actors. Agroforestry Systems, 93(5), 1961-1972.

FAO. (2013). Food Wastage Footprint: impacts on natural resources. Summary Report. Natural Resource Dept. Rome: FAO, 2013. http://www.fao.org/3/i3347e/i3347e.pdf

FAO. (2014). Sustainability Assessment of Food and Agriculture Systems. Guidelines Version 3.0. Roma: FAO. http://www.fao.org/3/a-i3957e.pdf

FAO. (2017). FAO Hails UN Resolutions Honoring Family Farmers, Bees, Camelids and Fisheries. Rome: FAO. http://www.fao.org/news/story/en/item/1073197/icod

FSIN. (2020). Global Report on Food Crises. https://www.fsinplatform.org/sites/default/files/resources/files/GRFC_2020_ONLINE_200420.pdf

Garibaldi, L. A., Gemmill-Herren, B., D’Annolfo, R., Graeub, B. E., Cunningham, S. A., \& Breeze, T. D. (2017). Farming Approaches for Greater Biodiversity, Livelihoods, and Food Security. Trends in Ecology and Evolution, 32(1), 68-80. https://pubmed.ncbi.nlm.nih.gov/27793463/

Gliessman, S. (2018). Defining Agroecology. Agroecology and Sustainable Food Systems, 42(6), 599-600.

Goswami, R., Saha, S., \& Dasgupta, P. (2017). Sustainability assessment of smallholder farms in developing countries. Agroecology and Sustainable Food Systems, 41(5), 546-569.

Graeub, B. E., Chappell, M. J., Wittman, H., Ledermann, S., Kerr, R. B., \& Gemmill-Herren, B. (2016). The State of Family Farms in the World. World Development, 87, 1-15. https://doi.org/10.1016/j.worlddev.2015.05.012

Guerra, J., Blesh, J., Schmitt Filho, A. L., \& Wittman, H. (2017). Pathways to agroecological management through mediated markets in Santa Catarina, Brazil. Elem Sci Anth, 5(67), 1-16. https://online.ucpress.edu/elementa/article/doi/10.1525/elementa.248/112446/Pathways-to-agroecological-management-through

Hilmi, A. (2019). The Alfredo Namitete agroecology credit system: A new business model that supports small-scale lending. Sustainability (Switzerland), $11(15)$.

IBGE. (2019). Ministério da Economia. Censo agropecuário 2017: resultados definitivos. Censo agropecuário, 8, 1-105. https://biblioteca.ibge.gov.br/visualizacao/periodicos/3096/agro_2017_resultados_definitivos.pdf

Jacobi, J., Mukhovi, S. M., Zonta, A. L., \& Augstburger, H. (2018). Operationalizing food system resilience: An indicator-based assessment in agroindustrial, smallholder farming, and agroecological contexts in Bolivia and Kenya. Land Use Policy, 79, 433-446.

Kangmennaang, J., Kerr, R. B., Lupafya, E., Dakishoni, L., Katundu, M., \& Luginaah, I. (2017). Impact of a participatory agroecological development project on household wealth and food security in Malawi. Food Security, 9, 561-576. https://link.springer.com/article/10.1007/s12571-017-0669-z

Krantz, L. (2001). The sustainable livelihood approach to poverty reduction: an introduction. Stockholm: Swedish International Development Policy (SIDA), Division for Policy and Socio-Economic Analysis.

Larrauri, O. de M., Neira, D. P., \& Montiel, M. S. (2016). Indicators for the analysis of peasant women's equity and empowerment situations in a sustainability framework: a case study of cacao production in Ecuador. Sustainability (Switzerland), 8(12). https://www.mdpi.com/2071-1050/8/12/1231/htm

Loyola, J. (2016). Conocimientos y prácticas ancestrales y tradicionales que fortalecen la sustentabilidad de los sistemas hortícolas de la parroquia de San Joaquín. La Granja: Revista de Ciencias de la Vida, 24(2), 29-42.

Lucantoni, D., González, A. J., Velázquez, I. R. A., \& Garcia, M. M. (2018). Conversión agroecológica para la seguridad y la soberanía alimentaria de una finca familiar. Agroecological conversion for the security and food sovereignty of a family farm, 6(1), 61-69.

Massicotte, M. J., \& Kelly-Bisson, C. (2019). What's wrong with permaculture design courses? Brazilian lessons for agroecological movement-building in Canada. Agriculture and Human Values, 36(3), 581-594. https://link.springer.com/article/10.1007/s10460-018-9870-8

Meert, H., Huylenbroeck, G. van, Vernimmen, T., Bourgeois, M., \& Hecke, E. (2005). Farm household survival strategies and diversification on marginal farms. Journal of Rural Studies, 21(1), 81-97.

Mthembu, B. E., Everson, T. M., \& Everson, C. S. (2019). Intercropping for enhancement and provisioning of ecosystem services in smallholder, rural farming systems in KwaZulu-Natal Province, South Africa: a review. Journal of Crop Improvement, 33(2), $145-176$.

Nicolay, G. L. (2019). Understanding and Changing Farming, Food \& Fiber Systems. The Organic Cotton Case in Mali and West Africa. Open Agriculture, 4, 86-97. https://doi.org/10.1515/opag-2019-0008 
SBGG. (2015, 2 Oct.). OMS Divulga Relatório sobre Envelhecimento e Saúde. Rio de Janeiro: Sociedade Brasileira de Geriatria e Gerontologia. https://sbgg.org.br/oms-divulga-relatorio-sobre-envelhecimento-e-saude/.

ONU. (2015). Transformando Nosso Mundo: A Agenda 2030 para o Desenvolvimento Sustentável. Organização das Nações Unidas, 14(2). https://bibliotecadigital.fgv.br/ojs/index.php/gvexecutivo/article/view/56854

Paraíba. Ministério de Estado do Desenvolvimento Agrário. Plano Territorial de Desenvolvimento Rural Sustentável: território da Borborema - PB. Resumo Executivo 2010-2020. http://sit.mda.gov.br/download/ptdrs/ptdrs_qua_territorio024.pdf

Petersen, P., Silveira, L. M. da, Dias, E., Curado, F., \& Santos, A. (2013). Sementes ou grãos? Lutas para desconstrução de uma falsa dicotomia. Revista Agriculturas: experiências em agroecologia, 10(1), 36-46. http://aspta.org.br/article/sementes-ou-graos-lutas-para-desconstrucao-de-uma-falsa-dicotomia/

Petersen, P., Silveira, L. M. da, Fernandes, G. B., \& Almeida, S. G. de. (2017). Método de análise econômico-ecológica de Agroecossistemas. Rio de Janeiro: AS-PTA.

Ploeg, J. D. van der. (2008). Camponeses e impérios alimentares: lutas por autonomia e sustentabilidade na era da globalização. v. 0.

Ploeg, J. D. van der, Barjolle, D., Bruil, J., Brunori, G., Madureira, L. M. C., Dessein, J., \& Wezel, A. (2019). The economic potential of agroecology: empirical evidence from Europe. Journal of Rural Studies, 46-61. https://biblio.ugent.be/publication/8631433

Rasse, C., Andrieu, N., Diman, J.-L., Fanchone, A., \& Chia, E. (2018). Utilisation de pratiques agroécologiques et performances de la petite agriculture familiale : le cas de la Guadeloupe. Cahiers Agricultures, 27(5), 1-10.

Saldanha, M. C. W., Silva, E. D., Carvalho, R. J. M., \& Araujo, I. O. (2016). Bases para a Elaboração de um Sistema de Indicadores de Desempenho para Agricultura Familiar Agroecológica no Território da Borborema. In: Carvalho, R. J. M. de, Saldanha, M. C. W., \& Vidal, M. C. R. (org.). Azimutes do Trabalho: olhares da ergonomia para diversas situações. Porto Alegre: Revolução e-Book, 176.

Saldanha, M. C. W., Carvalho, R. J. M. de, Silva, E. D., \& Araujo, I. O. de. (2018). Um método de desenvolvimento de um sistema de indicadores de desempenho para agricultura familiar agroecológica. Cadernos de Agroecologia - Anais do VI Congresso Latino-americano de Agroecologia; X Congresso Brasileiro de Agroecologia; V Seminário de Agroecologia do Distrito Federal e Entorno; 12 a 15 de setembro de 2017, Brasília/DF, 13(1), 1-7. http://cadernos.aba-agroecologia.org.br/cadernos/article/view/1535

Schneider, S. (2003). Teoria social, agricultura familiar e pluriatividade. Revista Brasileira de Ciências Sociais, 18(51).

Sobrinho, S. J., \& Ramos, N. L. (2016). Entre os saberes do povo e as sementes da paixão: Educação popular e agricultura familiar em Alagoa Nova (PB). Anais do II Congresso Internacional de Educação Inclusiva, II Jornada Chilena Brasileira de Educação Inclusiva, 16 a 18 de novembro de 2016, Raymundo Asfora, 1-12. https://www.editorarealize.com.br/artigo/visualizar/22928

Soldi, A., Meza, M. J. A., Guareschi, M., Donati, M., \& Ortiz, A. I. (2019). Sustainability Assessment of Agricultural Systems in Paraguay: A Comparative Study Using FAO’s SAFA Framework. Sustainability, 11(13). https://www.mdpi.com/2071-1050/11/13/3745

Solis, S. H. D., \& Rivera, R. M. (2018). Impact of good agricultural practices in the farm development in Los Palacios. Avances, 20(4), 401-412.

Teixeira, H. M., Berg, L. van den, Cardoso, I. M., Vermue, A. J., Bianchi, F. J. J. A., Peña-Claro, M., \& Tittonell, P. (2018). Understanding Farm Diversity to Promote Agroecological Transitions. Sustainability, 10(12), 1-20. https://doi.org/10.3390/su10124337

Thomazini, A., Azevedo, H. C. A. de, Pinheiro, P. L., \& Mendonça, E. de S. (2013). Indicadores participativos de qualidade do cafeeiro conilon e do solo em sistema agroflorestal e convencional. Bioscience Journal, 29(5), 1469-1478. https://seer.ufu.br/index.php/biosciencejournal/article/view/15103

Timmermann, C., \& Félix, G. F. (2015). Agroecology as a vehicle for contributive justice. Agriculture and Human Values, 32(3), 523-538.

Trevisan, A. C. D., Schmitt Filho, A. L., Farley, J., Fantini, A. C., \& Longo, C. (2016). Farmer perceptions, policy and reforestation in Santa Catarina, Brazil. Ecological Economics, 130, 53-63. https://ideas.repec.org/a/eee/ecolec/v130y2016icp53-63.html

UNEP. (2020, 13 July). How to feed 10 billion people. Nairobi: United Nations Environment Programme. https://www.unenvironment.org/news-andstories/story/how-feed-10-billion-people.

Vaarst, M., Escudero, A. G., Chappell, M. J., Brinkley, C., Nijbroek, R., \& Arraes, N. (2018). Exploring the concept of agroecological food systems in a cityregion context. Agroecology and Sustainable Food Systems, 42(6), p. 686-711. https://doi.org/10.1080/21683565.2017.1365321

Valencia, V., Wittman, H., \& Blesh, J. (2019). Structuring Markets for Resilient Farming Systems. Agronomy for Sustainable Development, 39(2), 1-14.

Williams, N. E., Carrico, A. R., Edirisinghe, I., \& Champika, J. A. J. (2018). Assessing the Impacts of Agrobiodiversity Maintenance on Food Security Among Farming Households in Sri Lanka's Dry Zone. Economic Botany, 72(2), 196-206.

Wittman, H., \& Blesh, J. (2017). Food Sovereignty and Fome Zero: Connecting Public Food Procurement Programmes to Sustainable Rural Development in Brazil. Journal of Agrarian Change, 17(1), 81-105. 